\title{
Mixed matrix membranes embedded with Janus mesoporous silica nanoparticles for highly efficient water treatment
}

\author{
Z. M. Mi ${ }^{1}$, D. W. Zhang ${ }^{2}$, D. M. Wang ${ }^{3}$, Z. X. Liu ${ }^{1 *}$ \\ ${ }^{1}$ Jiangxi Province Key Laboratory of Polymer Micro/Nano Manufacturing and Devices, School of Chemistry, Biology and \\ Materials Science, East China University of Technology, 330013 Nanchang, PR China \\ ${ }^{2}$ College of Chemistry and Pharmaceutical Engineering, Jilin Institute Chemical Technology, 132022 Jilin City, China \\ ${ }^{3}$ Key Laboratory of High Performance Plastics (Jilin University), Ministry of Education. National \& Local Joint \\ Engineering Laboratory for Synthesis Technology of High Performance Polymer. College of Chemistry, Jilin University, \\ 130012 Changchun, P. R. China
}

Received 2 July 2020; accepted in revised form 3 September 2020

\begin{abstract}
A periodic mesoporous organosilica (PMO) Janus nanoparticle ( $\left.\mathrm{PMO}-\mathrm{SO}_{3} \mathrm{H} \& \mathrm{SiO}_{2}-\mathrm{NR}\right)$ was gently synthesized and mixed with polyethersulfone (PES) to fabricate a series of mixed matrix membranes via the phase inversion method. The Janus structure of $\mathrm{PMO}-\mathrm{SO}_{3} \mathrm{H} \& \mathrm{SiO}_{2}-\mathrm{NR}$ nanoparticle enabled the hydrophilic $-\mathrm{SO}_{3} \mathrm{H}$ and hydrophobic hexadecyl (-NR) to be separately distributed on the PMO cores and $\mathrm{SiO}_{2}$ branches, and hence Janus PMO- $\mathrm{SO}_{3} \mathrm{H} \& \mathrm{SiO}_{2}-\mathrm{NR}$ nanoparticle was endowed with good hydrophilicity and excellent compatibility with PES membrane matrix. As a result, the mixed matrix membranes presented improved bulk porosity, surface mean pore size, hydrophilicity and permeability. Particularly, the pure water flux of the mixed matrix membrane with $5 \mathrm{wt} \%$ porous Janus $\mathrm{PMO}-\mathrm{SO}_{3} \mathrm{H} \& \mathrm{SiO}_{2}-\mathrm{NR}$ nanoparticles (M5) was as high as $330 \mathrm{l} \cdot \mathrm{m}^{-2} \cdot \mathrm{h}^{-1}$ that was 2.2 times that of the pristine PES ultrafiltration (UF) membrane (M0) while its rejection for bovine serum albumin (BSA) remained above 98.0\%. Besides, after multi-cycles UF experiment with BSA as model contaminant, M5 retained a high flux recovery rate, permeation flux and rejection, suggesting its outstanding overall performance. Porous Janus $\mathrm{PMO}-\mathrm{SO}_{3} \mathrm{H} \& \mathrm{SiO}_{2}-\mathrm{NR}$ nanoparticle is the first time to be used as an effective additive to prepare mixed matrix membrane, providing a new approach to achieve highly efficient water treatment of UF membranes.
\end{abstract}

Keywords: polymer membranes, porous Janus nanoparticle, ultrafiltration, hydrophilicity, compatibility

\section{Introduction}

Ultrafiltration (UF) has become a common method for industrial water treatment, including the concentration, purification and separation of macromolecular substances in the chemical, food and pharmaceutical industries $[1,2]$. Polyethersulfone (PES) is one of the most popular UF membrane materials owing to its high mechanical strength, excellent chemical resistance, good dimensional stability, heat resistance, ideal biocompatibility, etc. [3, 4]. Nonetheless, the application of PES UF membrane to water treatment is greatly limited due to the low permeability and severe membrane fouling. The low permeability is mainly related to the less porosity of membrane, and membrane fouling is derived from the natural hydrophobicity of PES susceptible to the adhesion or deposition of proteins and natural organic matter [5]. Therefore, it is entirely justified to increase the porosity and hydrophilicity of the membrane to improve the efficiency of PES UF membrane water treatment. Among numerous reported modifications like chemical grafting, surface coating, membrane material 
modification etc. [6-10], the blending is preferred because of its easy operation, simple process, low cost and immediate effect $[11,12]$. With the emergence of nanomaterials, hydrophilic nanomaterials such as nanoparticles [13], nanotubes [14], nanowires [15] and nanosheets [16] have become the most commonly used blending filler to prepare mixed matrix membranes. It is well established that the hydrophilic nanomaterials blended in polymer matrix can not only affect the thermodynamic and kinetic behavior of the casting solution facilitating the formation of porous structure and hence the improvement of water flux of UF membrane, but also spontaneously migrate to the membrane surface to enhance the hydrophilicity and hence inhibit membrane fouling. Unfortunately, inhomogeneous dispersion of most inorganic nanomaterials in polymer membrane matrix is always an invariably thorny issue due to their own easily induced aggregation and their poor compatibility with the organic polymer membrane matrix [17]. Consequently, these mixed matrix membranes inevitably suffer from local defects and pore blockage resulting in the reduced rejection and inferior membrane permeability. This completely defeats the purpose of blending nanomaterials into the polymer membrane matrix. Therefore, more researchers start to directly synthesize organic nanoparticles or modify inorganic nanomaterials with organic compounds or polymers to obtain organic-inorganic hybrid nanomaterials so as to weaken the agglomeration of inorganic nanomaterials and enhance their compatibility with polymer membrane matrix [12, 17-19]. However, due to the limited types of organic nanoparticles and the negative impact of the hydrophobic segments of the organic-inorganic nanomaterials on the membrane hydrophilicity, novel or unconventional nanomaterials need to be developed to further extend the research methods of improving the permeability and antifouling performance of UF membrane.

At the Nobel Prize conference in 1991, the term 'Janus' was firstly used by Prof. De Gennes to describe an asymmetric structure containing two different chemical compositions or different polarities in the same matter [20]. Due to the structural asymmetry and compositional diversity of Janus-type nanomaterials (nanosheets [5], nanofibers [21], nanomembranes [22] etc.), they are gradually attracting more researchers' attention and showing potential application value in many fields such as drug release [23], water treatment [24], photocatalysis [25], batteries
[26] as well as photoelectricity [27]. In terms of their application in water treatment, for example, Zhao et al. [22] reported a solar-powered Janus membrane ( $88 \%$ energy conversion efficiency) for the efficient decontaminations of sewage, involving organic dyes, heavy metal ions, and pathogens (bacteria, viruses, parasites). Hu et al. [28] fabricated the magnetic Janus nanoparticles (M-Janus NPs) of asymmetric surface wettability, and these nanoparticles could anchor more firmly at the oil-water interface, leading to more effective treatment of oily wastewaters and removal/recovery of waste oil in comparison with biwettable magnetic NPs of uniform surface wettability. Akbari et al. [5] synthesized Janus graphene oxide (Janus GO) nanosheets by Pickering emulsion method, and GO and Janus GO were separately used as blending fillers to prepare the mixed matrix membranes by phase inversion. Compared with the membrane GO-1, Janus-1 had the greater improvement in flux, hydrophilicity and antifouling performance due to the asymmetry in the chemical composition of Janus GO nanosheet composed of a hydrophobic portion and a hydrophilic portion. In addition to Janus GO nanosheet, novel Janus nanomaterials that can be used to improve the permeability and antifouling performance of UF membranes are still being developed and explored. For example, we recently found a Janus mesoporous silica with sprout-like nanostructure (PMO and $\mathrm{SiO}_{2}$ ), which was firstly synthesized by Wang et al. [29] via a simple and generalizable sprout-like growth method using periodic mesoporous organosilica (PMO) nanoparticles as seeds with mesoporous $\mathrm{SiO}_{2}$ as branches growing on the PMO surface. Fortunately, the porous Janus $\mathrm{PMO}_{\mathrm{SiO}} \mathrm{Sin}_{2}$ nanoparticle can be also easily modified with different groups on the PMO cores and $\mathrm{SiO}_{2}$ branches to fabricate the organic-inorganic hybrid $\mathrm{PMO} \& \mathrm{SiO}_{2}$ nanoparticles, respectively. Versus other nanomaterials, e.g. Janus GO nanosheet, organic-inorganic hybrid $\mathrm{PMO} \& \mathrm{SiO}_{2}$ nanoparticle has not only the diversity of components but also the structural asymmetry as well as porosity. These are of great significance for a blending filler to regulate the morphology and further improve the performance of the PES UF membrane. Yet, no one has ever reported porous Janus $\mathrm{PMO} \& \mathrm{SiO}_{2}$ nanoparticle or organicinorganic hybrid $\mathrm{PMO} \& \mathrm{SiO}_{2}$ nanoparticle as the blending filler to improve the hydrophilicity, permeation flux and antifouling performance of PES UF membrane. 


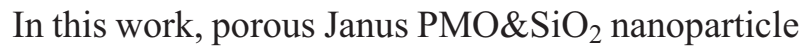
was facially synthesized according to the procedures described in the literature [29]; subsequently, porous Janus $\mathrm{PMO}-\mathrm{SO}_{3} \mathrm{H} \& \mathrm{SiO}_{2}-\mathrm{NH}_{2}$ nanoparticle was obtained by decorating (3-mercaptopropyl)trimethoxysilane and 3-aminopropyltriethoxysilane on the PMO cores and $\mathrm{SiO}_{2}$ branches, respectively; finally, palmitoyl chloride reacted with the $-\mathrm{NH}_{2}$ of $\mathrm{PMO}-\mathrm{SO}_{3} \mathrm{H} \&$ $\mathrm{SiO}_{2}-\mathrm{NH}_{2}$ to obtain PMO-SO $3 \mathrm{H}_{2} \mathrm{SiO}_{2}-\mathrm{NR}$. Figure 1 shows a schematic diagram of the preparation of porous Janus $\mathrm{PMO}-\mathrm{SO}_{3} \mathrm{H} \& \mathrm{SiO}_{2}-\mathrm{NR}$ nanoparticle. Different amounts of porous Janus $\mathrm{PMO}-\mathrm{SO}_{3} \mathrm{H} \&$ $\mathrm{SiO}_{2}$-NR nanoparticles were mixed with PES to prepare mixed matrix membranes via the phase inversion method. Porous Janus $\mathrm{PMO}-\mathrm{SO}_{3} \mathrm{H} \& \mathrm{SiO}_{2}-\mathrm{NR}$ nanoparticle was selected as blending filler in view of the following aspects: (1) the porosity of the Janus $\mathrm{PMO}-\mathrm{SO}_{3} \mathrm{H} \& \mathrm{SiO}_{2}$-NR nanoparticle itself with an average pore diameter of $\sim 2 \mathrm{~nm}$ as well as the tiny voids between the porous Janus nanoparticles and the membrane matrix are likely to provide additional transmission channels for water molecules, which is very beneficial to improve the permeation flux of UF membrane [17]. (2) the structural asymmetry brought by the sprout-like growth method enables the hydrophilic $-\mathrm{SO}_{3} \mathrm{H}$ and hydrophobic hexadecyl (-NR) to be distributed on the PMO cores and $\mathrm{SiO}_{2}$ branches, respectively. The hydrophobic hexadecyl on $\mathrm{SiO}_{2}$ branches can effectively impede the agglomeration of Janus PMO-SO $\mathrm{SH}_{3} \mathrm{H} \mathrm{SiO}_{2}$-NR nanoparticles and enhance their compatibility with the membrane matrix, advoiding the appearance of non-defective voids and the leak of Janus nanoparticles. The hydrophilic $\mathrm{PMO}-\mathrm{SO}_{3} \mathrm{H}$ core can directionally and spontaneously migrate to the membrane surface, which contributes to the improvement of the hydrophilicity, permeation flux and antifouling performance of the UF membrane. In comparison, mixed matrix membrane doped with porous Janus $\mathrm{PMO}_{2} \mathrm{SiO}_{2}$ nanoparticle was also prepared by the same method. Therefore, the incorporation of porous Janus nanoparticles into the PES membrane matrix is expected to improve the hydrophilicity, permeation flux, and antifouling performance of the PES UF membranes.

\section{Experimental}

\subsection{Materials}

Bis(triethoxysilyl)ethane (BTEE, 99\%), hexadecyl trimethyl ammonium bromide (CTAB, 98\%), tetraethoxysilane (TEOS, 98\%), 3-aminopropyltriethoxysilane (APTES, 98\%), (3-mercaptopropyl)trimethoxysilane (MPTMS, 99\%), palmitoyl chloride (99\%),

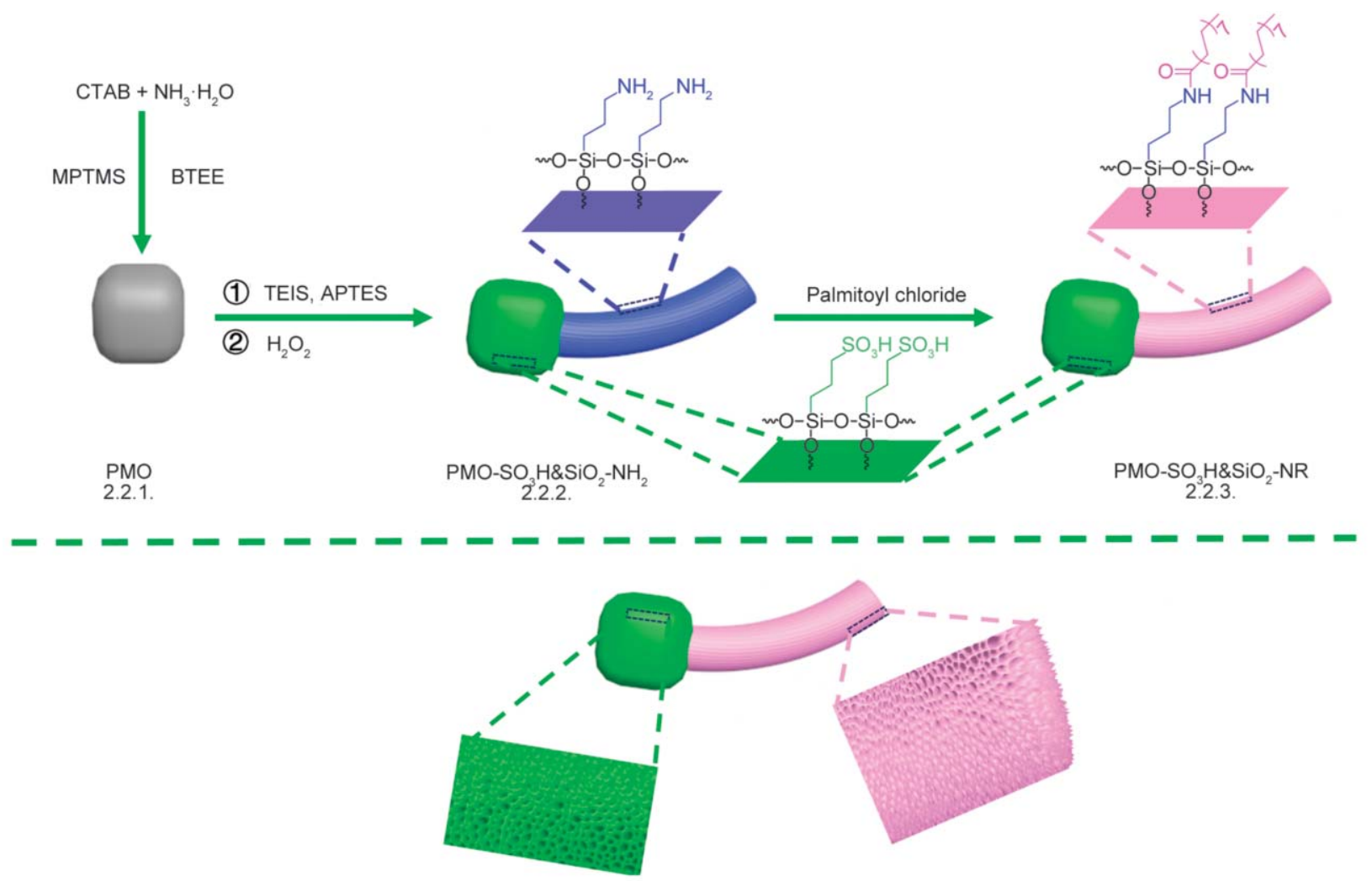

Figure 1. Schematic diagram of the preparation of porous Janus $\mathrm{PMO}-\mathrm{SO}_{3} \mathrm{H} \& \mathrm{SiO}_{2}-\mathrm{NR}$ nanoparticle.

Note: the lower part of the dashed line is the model of the Janus PMO- $\mathrm{SO}_{3} \mathrm{H} \& \mathrm{SiO}_{2}-\mathrm{NR}$ nanoparticle structure. 
hydrogen peroxide solution $\left(\mathrm{H}_{2} \mathrm{O}_{2}, 30 \mathrm{wt} \%\right)$ and ammonium hydroxide $\left(\mathrm{NH}_{3} \cdot \mathrm{H}_{2} \mathrm{O}, 27 \mathrm{wt} \%\right)$ were supplied by Aldrich Chemical Co. (Shanghai, China) and used as received. Polyethersulfone (PES, $M_{\mathrm{w}}=$ 58000) was purchased from BASF Chemical Co. (Germany) and directly used. Bovine serum albumin (BSA, 96\%) was obtained from Aladdin Chemical Reagent Co. (Shanghai, China). N,N-Dimethylformamide (DMF) was purified by vacuum distillation over $\mathrm{CaH}_{2}$ and stored over $4 \AA$ molecular sieves prior to use. Deionized water was obtained from hollow fiber reverse osmosis device and used throughout the experiments. The other commercially available solvents and reagents were obtained from Xilong Chemical Reagent Guangdong Co. Ltd. (Guangdong, China) and used without further purification.

\subsection{Synthesis of porous Janus nanoparticles}

\subsubsection{Synthesis of porous Janus PMO\&SiO nanoparticle}

Porous Janus $\mathrm{PMO}_{2} \mathrm{SiO}_{2}$ nanoparticle was synthesized according to the method reported in the literature [29]. Briefly, hexadecyl trimethyl ammonium bromide $(0.021 \mathrm{~g}), \mathrm{NH}_{3} \cdot \mathrm{H}_{2} \mathrm{O}(0.26 \mathrm{ml})$ and water $(9.74 \mathrm{ml})$ were transferred into a $20 \mathrm{ml}$ of vial, the mixture was sonicated for $15 \mathrm{~min}$ at $25^{\circ} \mathrm{C}$ to form a clear solution. Subsequently, the solution was stirred in an oil bath at $50^{\circ} \mathrm{C}$ for $10 \mathrm{~min}$, and BTEE $(140 \mu \mathrm{l}$, $0.5 \mathrm{~mol} / 1$ in ethanol) was added dropwise in $5 \mathrm{~min}$ and the solution was continuously stirred for $2 \mathrm{~h}$. Then, hexadecyl trimethyl ammonium bromide $(0.03 \mathrm{~g})$ and $\mathrm{NH}_{3} \cdot \mathrm{H}_{2} \mathrm{O}(0.4 \mathrm{ml})$ were added at $40^{\circ} \mathrm{C}$, and tetraethoxysilane $(50 \mu \mathrm{l})$ was gradually dripped into the mixture, after approximately $30 \mathrm{~min}$, a heterogeneous white mixture was obtained and kept stirring to room temperature. The product was collected by centrifugation and washed three times with deionized water, and refluxed in $40 \mathrm{ml}$ of ethanol to remove the surfactant.

\subsubsection{Synthesis of porous Janus}

\section{$\mathrm{PMO}_{-} \mathrm{SO}_{3} \mathrm{H} \& \mathrm{SiO}_{2}-\mathrm{NH}_{2}$ nanoparticle}

A mixture of (3-mercaptopropyl)trimethoxysilane $(30 \mu \mathrm{l})$ and BTEE $(1.4 \mathrm{ml}, 0.5 \mathrm{~mol} / \mathrm{l}$ in ethanol) was added dropwise into a vial containing an aqueous mixture of water $(97 \mathrm{ml})$, hexadecyl trimethyl ammonium bromide $(0.21 \mathrm{~g})$ and $\mathrm{NH}_{3} \cdot \mathrm{H}_{2} \mathrm{O}(2.6 \mathrm{ml}$. After stirring at $50^{\circ} \mathrm{C}$ in an oil bath for $2 \mathrm{~h}$, the reactant was cooled to $40^{\circ} \mathrm{C}$, additional hexadecyl trimethyl ammonium bromide $(0.3 \mathrm{~g})$ and $\mathrm{NH}_{3} \cdot \mathrm{H}_{2} \mathrm{O}$
(4 ml) were added and the resultant mixture was kept stirring for $0.5 \mathrm{~h}$. Subsequently, a mixed liquid of 3-aminopropyltriethoxysilane $(35 \mu \mathrm{l})$ and tetraethoxysilane $(0.5 \mathrm{ml})$ was added dropwise. After $0.5 \mathrm{~h}$, the white powder was centrifuged out and washed three times with deionized water. To remove the surfactant, the product was dispersed in $500 \mathrm{ml}$ of ethanol and refluxed for $24 \mathrm{~h}$, yielding porous Janus PMO$\mathrm{SH} \& \mathrm{SiO}_{2}-\mathrm{NH}_{2}$ nanoparticle.

For the synthesis of porous Janus PMO- $\mathrm{SO}_{3} \mathrm{H} \&$ $\mathrm{SiO}_{2}-\mathrm{NH}_{2}$ nanoparticle, $\mathrm{PMO}-\mathrm{SH} \& \mathrm{SiO}_{2}-\mathrm{NH}_{2}(1 \mathrm{~g})$ was first ultrasonically dispersed in ethanol $(50 \mathrm{ml})$ for 30 min under inert atmosphere. Subsequently, diluted $\mathrm{H}_{2} \mathrm{O}_{2}(10 \mathrm{wt} \%, 15 \mathrm{ml})$ was carefully added dropwise at $0{ }^{\circ} \mathrm{C}$ and stirred for another $2 \mathrm{~h}$. After centrifugation, the resulting powder was transferred into dilute hydrochloric acid $(200 \mathrm{ml}, 0.1 \mathrm{~mol} / \mathrm{l})$ and refluxed for $3 \mathrm{~h}$ to produce fine powder.

\subsubsection{Synthesis of porous Janus

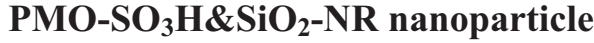

$\mathrm{PMO}-\mathrm{SO}_{3} \mathrm{H} \& \mathrm{SiO}_{2}-\mathrm{NH}_{2}(1 \mathrm{~g})$ and hexadecanoyl chloride $(0.1 \mathrm{~g})$ were suspended in $50 \mathrm{ml}$ of $n$-hexane. The mixture was stirred at room temperature for $5 \mathrm{~h}$ and then centrifuged, and the crude product was washed thoroughly with $n$-hexane to give off-white powder. All nanoparticles were dried in a vacuum oven for $24 \mathrm{~h}$ and stored in a desiccator for later use.

\subsection{Preparation of the mixed matrix membranes}

All the UF membranes were fabricated based on phase inversion method as previously reported [30]. Typically, for M1, porous Janus $\mathrm{PMO}-\mathrm{SO}_{3} \mathrm{H} \& \mathrm{SiO}_{2}-$ NR nanoparticle $(0.2 \mathrm{~g})$ was dispersed into DMF (75 g) and ultrasonicated for $45 \mathrm{~min}$, followed by the addition of PES (20 g) and PVP (5 g). The mixture was kept stirring at room temperature for $4 \mathrm{~h}$ to obtain transparent solution. After sufficient degasification in vacuum, the solution was cast onto a flat glass plate using a knife with the gap at $100 \mu \mathrm{m}$. After 30 seconds, the glass plate was immersed in deionized water for $48 \mathrm{~h}$ to ensure that DMF was thoroughly exchanged to form a complete pore structure. Similarly, UF membranes with different amounts of porous Janus nanoparticles including M0, M3, M5 and M3' were obtained using the method mentioned above, and the compositions and photographs of casting solutions were decipted in Table 1 and Figure 2, respectively. 

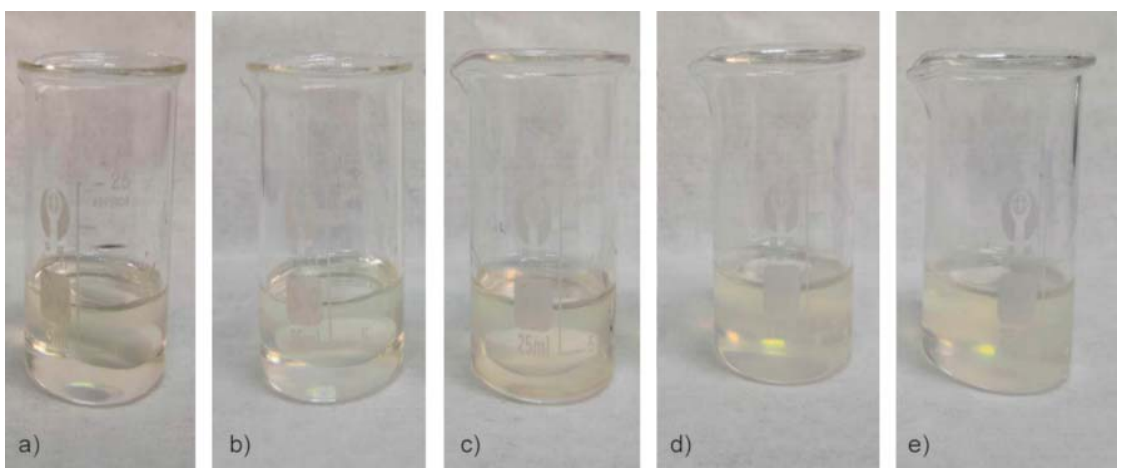

Figure 2. Casting solution of the hybrid membranes. The corresponding UF membranes were a) for M0, b) for M3, c) for M5, d) for M7 and e) for M5'.

Table 1. Compositions of casting solutions for the mixed matrix membranes.

\begin{tabular}{|c|c|c|c|c|c|}
\hline \multirow{2}{*}{ Membrane } & \multirow{2}{*}{$\begin{array}{c}\text { PES } \\
{[\%]}\end{array}$} & \multirow{2}{*}{$\begin{array}{c}\text { PVP } \\
{[\%]}\end{array}$} & \multirow{2}{*}{$\begin{array}{c}\text { DMF } \\
{[\%]}\end{array}$} & \multicolumn{2}{|c|}{$\begin{array}{c}\text { Porous Janus nanoparticles }^{\mathrm{b}} \\
\text { [\%] }\end{array}$} \\
\cline { 5 - 6 } & & & & $\mathbf{S i O}_{2}$ \&PMO & - \\
\hline M0 & 20 & 5 & 75 & $-{ }^{\mathrm{a}}$ & 1 \\
\hline M1 & 20 & 5 & 75 & - & 3 \\
\hline M3 & 20 & 5 & 75 & - & 5 \\
\hline M5 & 20 & 5 & 75 & - & - \\
\hline M3' & 20 & 5 & 75 & 3 & PMO-SiO $_{2}$-NR $^{\prime}$ \\
\hline
\end{tabular}

${ }^{a}$ No substance added.

${ }^{b}$ Mass ratio of Janus nanoparticles to PES

\subsection{Characterization}

FTIR spectra were recorded on a Thermal Scientific Nicolet 380 spectrometer at a resolution of $4 \mathrm{~cm}^{-1}$ in the range of $500-4000 \mathrm{~cm}^{-1}$. Thermogravimetric analysis (TGA) was conducted on Netzsch STA2500 under nitrogen atmosphere with a heating rate of $10^{\circ} \mathrm{C} \cdot \mathrm{min}^{-1}$ from 50 to $810^{\circ} \mathrm{C}$. X-ray photoelectron spectroscopy (XPS) was performed using ESCALAB 250 with a resolution of $0.46 \mathrm{eV} /(\mathrm{C} 1 \mathrm{~s})$. The morphologies of porous Janus nanoparticles and membranes were carried out with field emission electron microscope (FEI Nova Nano SEM 450). BrunauerEmmett-Teller (BET) surface areas and pore volumes of the Janus nanoparticles were assessed by Quantachrome Instruments with the model of Autosorb IQ-MP (1 stat.) viton at $77 \mathrm{~K}$. The surface mean pore size of the membrane was obtained from the magnified SEM image by Nano Measure software. The roughness of the membrane surface was determined on a NT-MDT Solver Next atomic force microscopy (AFM). The scanning frequency, scanning times and scanning area were selected at $1 \mathrm{~Hz}$, 256 and $10 \mu \mathrm{m} \times 10 \mu \mathrm{m}$, respectively. The average value of the ordinate parameters at the $128^{\text {th }}$ scan was taken to calculate the roughness. The hydrophilicity of the membranes was detected by the water contact angle studies of the membranes - these were measured on a drop shape analysis system DSA10MK2 at $25^{\circ} \mathrm{C}$. Each sample was tested five times in different positions, and the average of five replicates was taken as the result.

Porosity of membranes is evaluated by formula presented in Equation (1):

Porosity $[\%]=\frac{W_{\mathrm{w}}-W_{\mathrm{d}}}{d A \rho_{\mathrm{w}}} \cdot 100$

where $W_{\mathrm{w}}$ and $W_{\mathrm{d}}$ are the weight of wet and dry membranes [g], respectively. $d$ is the thickness [cm] of the wet membranes. $A$ is the area of membranes $\left[\mathrm{cm}^{2}\right]$, and $\rho_{\mathrm{w}}$ is the density of water $\left[\mathrm{g} / \mathrm{cm}^{3}\right]$.

Cross-flow filtration experiment (Figure 3) was carried out using a TYLG-18 flat membrane experimental equipment (Bona Co. Ltd. Shandong, China) with the diaphragm diameter at $4.5 \mathrm{~cm}$. Each membrane was pre-pressed at $0.15 \mathrm{MPa}$ for $0.5 \mathrm{~h}$ prior to testing. Afterwards, the maintained pressure was adjusted to $0.1 \mathrm{MPa}$ throughout the test. In detail, pure water firstly went through the membrane at $0.1 \mathrm{MPa}$ for $1 \mathrm{~h}$, the water flux was recorded every 5 minutes with the stable water flux denoted as $J_{\mathrm{w}, 1}$. Subsequently, the pure water was replaced with BSA solution $(1 \mathrm{~g} / \mathrm{L})$ and passed through the membrane for $1 \mathrm{~h}$ with the stable flux recorded as $J_{\mathrm{p}, 1}$. Then the membrane was soaked and washed using pure water 


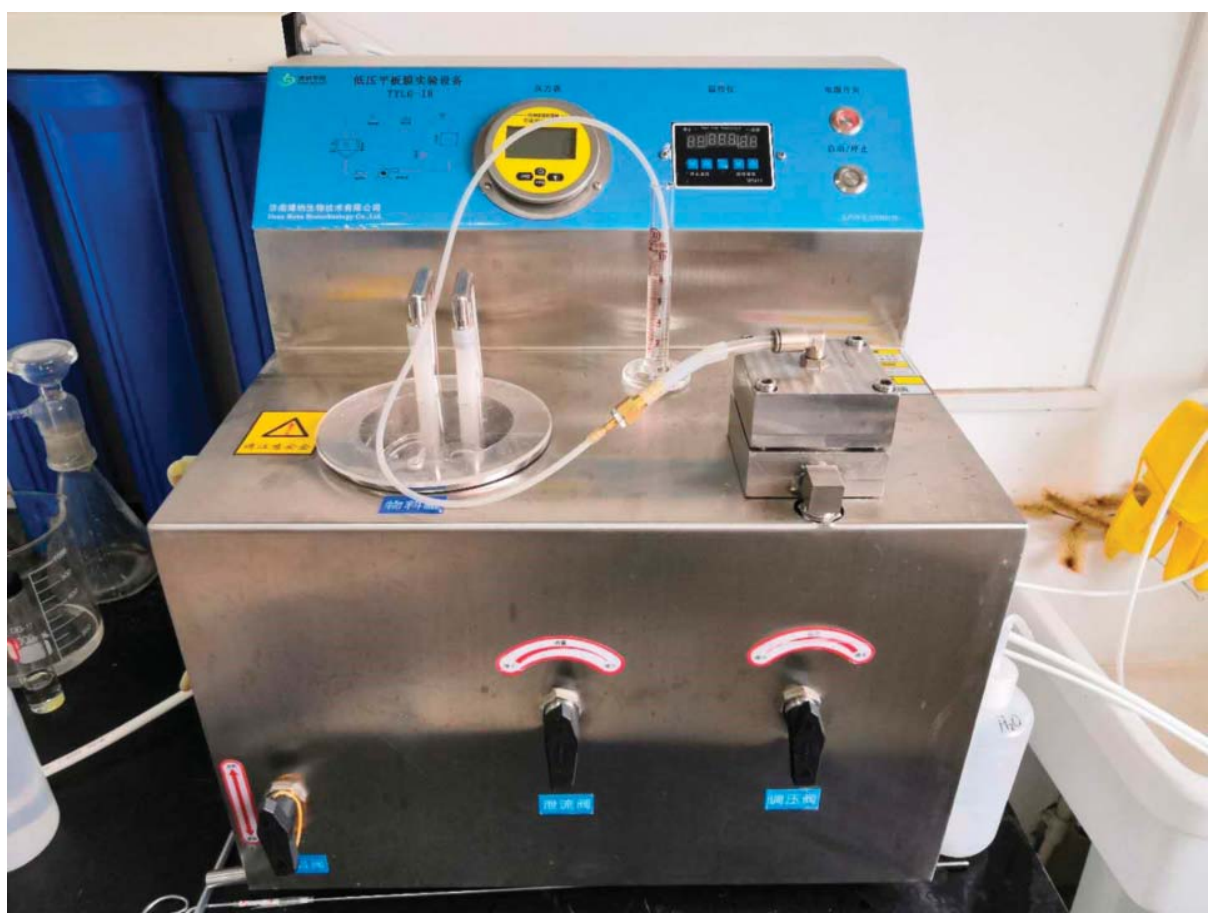

Figure 3. Cycle UF experiment equipment used in the water treatment.

for $0.5 \mathrm{~h}$, and the pure water passed through again for another $1 \mathrm{~h}$ with a stable flux at $J_{\mathrm{w}, 2}$. For each type membrane, five specimens were fabricated and tested under the same conditions to get statistics on permeation flux, antifouling performance, and rejection. The resultant parameters were the average of the five replicates, and the error bars indicated the standard deviation of the five sets of data.

Permeation fluxes including $J_{\mathrm{w}, 1}, J_{\mathrm{w}, 2}$ and $J_{\mathrm{p}, 1}$ are calculated by Equation (2):

$J=\frac{V}{A t}$

where $V$ is the permeation volume [1], $A$ is the membrane area $\left[\mathrm{m}^{2}\right]$, and $t$ is the permeation time $[\mathrm{h}]$. In this study, BSA was chosen as the model contaminant $(1 \mathrm{~g} / \mathrm{l})$ to evaluate the rejection and antifouling performance of the resultant UF membranes. The BSA rejection $(R)$ is calculated by Equation (3):

$R[\%]=1-\frac{C_{\mathrm{p}}}{C_{\mathrm{f}}}$

where $C_{\mathrm{p}}$ and $C_{\mathrm{f}}$ are permeation and feed concentration of BSA solution, respectively. $C_{\mathrm{p}}$ is obtained by UV-Vis analysis (UV 3600, Shimadzu).

The antifouling parameters including the flux recovery rate $(F R R)$, total fouling rate $\left(R_{\mathrm{t}}\right)$, irreversible fouling rate $\left(R_{\mathrm{ir}}\right)$ and reversible fouling rate $\left(R_{\mathrm{r}}\right)$ are calculated according to Equation (4)-(7), respectively:

$$
\begin{aligned}
& F R R[\%]=\frac{J_{\mathrm{w}, 2}}{J_{\mathrm{w}, 1}} \cdot 100 \\
& R_{\mathrm{t}}[\%]=\frac{J_{\mathrm{w}, 1}-J_{\mathrm{p}, 1}}{J_{\mathrm{w}, 1}} \cdot 100 \\
& R_{\mathrm{ir}}[\%]=\frac{J_{\mathrm{w}, 1}-J_{\mathrm{w}, 2}}{J_{\mathrm{w}, 1}} \cdot 100 \\
& R_{\mathrm{r}}[\%]=R_{\mathrm{t}}-R_{\mathrm{ir}}
\end{aligned}
$$

\section{Results and discussion}

\subsection{Characterization of porous Janus $\mathrm{PMO}_{2} \mathrm{SiO}_{2}, \mathrm{PMO}_{-} \mathrm{SO}_{3} \mathrm{H} \& \mathrm{SiO}_{2}-\mathrm{NH}_{2}$ and $\mathrm{PMO}_{-} \mathrm{SO}_{3} \mathrm{H} \& \mathrm{SiO}_{2}$-NR nanoparticles}

Characterizations including FTIR, XPS, BET and SEM were utilized to identify the successful preparation of porous Janus nanoparticles from various perspectives. Figure 4 decipits the FTIR spectra of three porous Janus nanoparticles $\left(\mathrm{PMO}_{2} \mathrm{SiO}_{2}\right.$, $\left.\mathrm{PMO}-\mathrm{SO}_{3} \mathrm{H} \& \mathrm{SiO}_{2}-\mathrm{NH}_{2}, \mathrm{PMO}-\mathrm{SO}_{3} \mathrm{H} \& \mathrm{SiO}_{2}-\mathrm{NR}\right)$. Characteristic absorption peaks near 1069 and $690 \mathrm{~cm}^{-1}$ belonged to the stretching vibration of $\mathrm{Si}-\mathrm{O}-\mathrm{Si}$ and $\mathrm{Si}-\mathrm{C}$, respectively, and the peaks appeared around 2930, $2856 \mathrm{~cm}^{-1}$ (aliphatic $\sigma(\mathrm{C}-\mathrm{H})$ ), $1405 \mathrm{~cm}^{-1}$ (aliphatic $\beta(\mathrm{C}-\mathrm{H})$ ) and $786 \mathrm{~cm}^{-1}$ (aliphatic $\gamma(\mathrm{C}-\mathrm{H})$ ) was probably originated from the $-\mathrm{CH}_{2}$ in BTEE fragments [31]. These demonstrated the existence of PMO structure. The vibration peaks of hydroxyl groups at $3435 \mathrm{~cm}^{-1}(\sigma(\mathrm{O}-\mathrm{H}))$ and $1630 \mathrm{~cm}^{-1}$ 

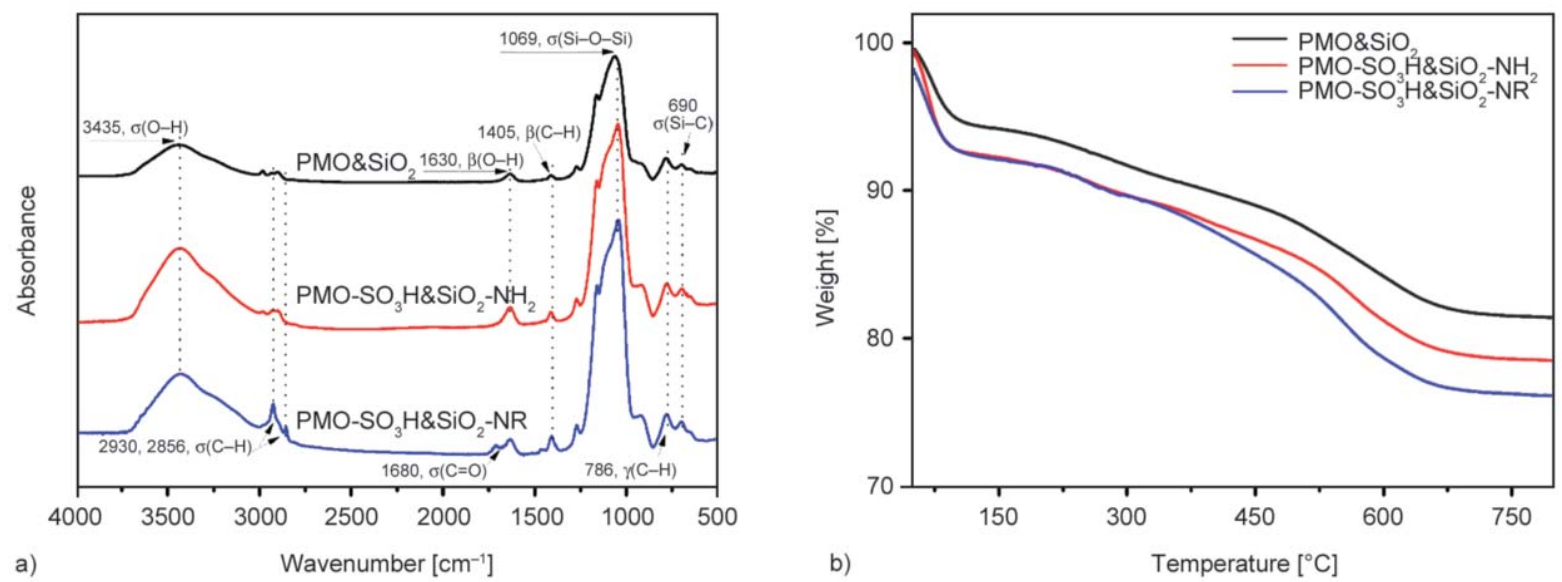

Figure 4. FTIR spectra (a) and TGA curves (b) of porous Janus $\mathrm{PMO} \& \mathrm{SiO}_{2}, \mathrm{PMO}-\mathrm{SO}_{3} \mathrm{H} \& \mathrm{SiO}_{2}-\mathrm{NH}_{2}, \mathrm{PMO}-\mathrm{SO}_{3} \mathrm{H} \& \mathrm{SiO}_{2}-\mathrm{NR}$ nanoparticles . Note: $\sigma$ : Stretching vibration; $\beta$ : In-plane bending vibration; $\gamma$ : Out-of-plane bending vibration.

$(\beta(\mathrm{O}-\mathrm{H}))$ were likely assigned to the associative hydrogen bond between silica and hydroxyl or water molecules, suggesting $\mathrm{PMO} \& \mathrm{SiO}_{2}$ owning certain hydrophilicity. Versus $\mathrm{PMO} \& \mathrm{SiO}_{2}$, the FTIR spectrum of $\mathrm{PMO}-\mathrm{SO}_{3} \mathrm{H} \& \mathrm{SiO}_{2}-\mathrm{NH}_{2}$ had no obvious change because characteristic absorption peaks of

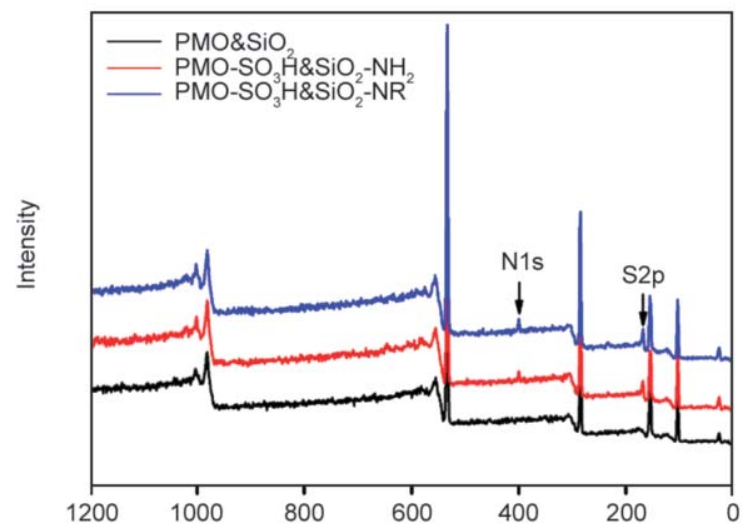

a)

Binding energy $[\mathrm{eV}]$

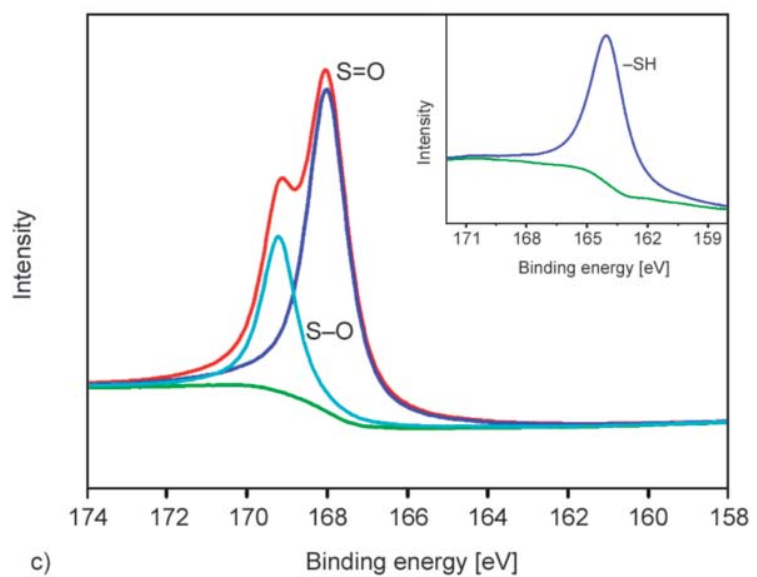

$-\mathrm{NH}_{2}\left(\sim 3400 \mathrm{~cm}^{-1} \sigma(\mathrm{N}-\mathrm{H}), 1635 \mathrm{~cm}^{-1}(\beta(\mathrm{N}-\mathrm{H}))\right.$ and $-\mathrm{SO}_{3} \mathrm{H}\left(1150\right.$ and $\left.1320 \mathrm{~cm}^{-1}, \mathrm{O}=\mathrm{S}=\mathrm{O}\right)$ were blanketed by the broad and strong peak of $-\mathrm{OH}$ and $\mathrm{Si}-\mathrm{O}-\mathrm{Si}$, respectively. The existence of $-\mathrm{SO}_{3} \mathrm{H}$ and $-\mathrm{NH}_{2}$ will be proved by the following XPS spectra (Figure 5). Versus $\mathrm{PMO}-\mathrm{SO}_{3} \mathrm{H} \& \mathrm{SiO}_{2}-\mathrm{NH}_{2}$, the FTIR
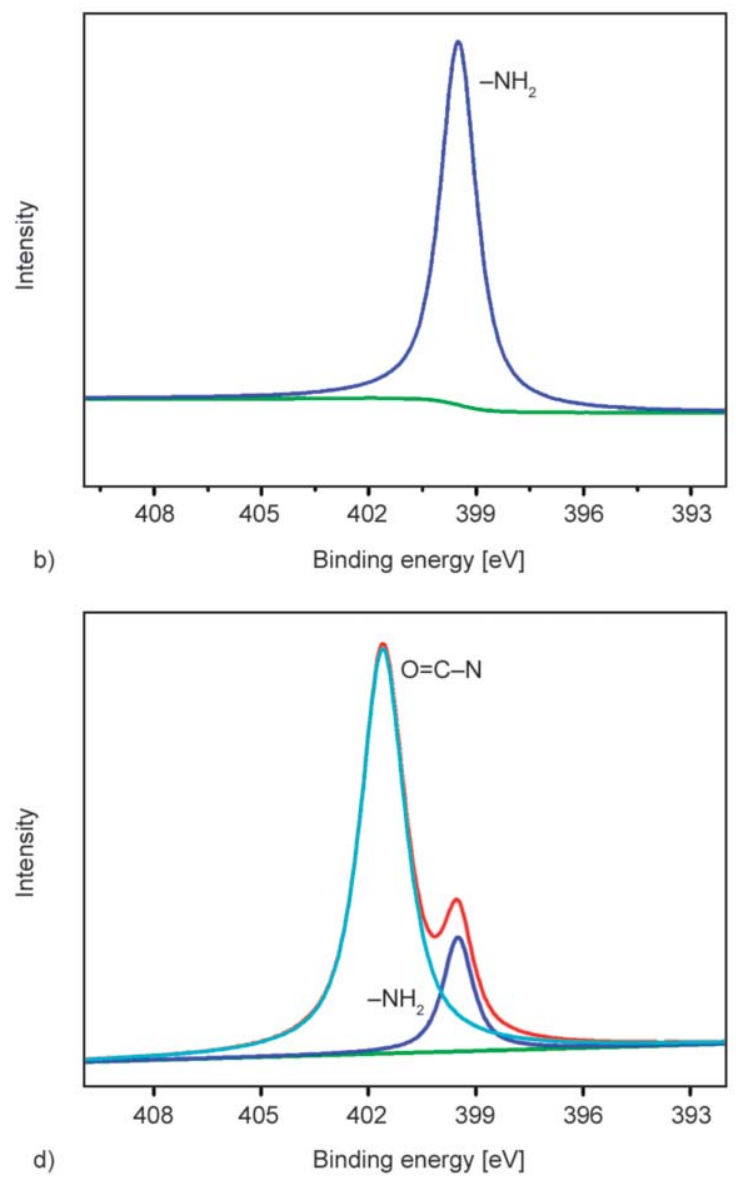

Figure 5. XPS wide-scan spectra (a) of porous Janus $\mathrm{PMO} \& \mathrm{SiO}_{2}, \mathrm{PMO}-\mathrm{SO}_{3} \mathrm{H} \& \mathrm{SiO}_{2}-\mathrm{NH}_{2}, \mathrm{PMO}-\mathrm{SO}_{3} \mathrm{H} \& \mathrm{SiO} 2-\mathrm{NR}$ nanoparticles. Curves fitting of N1s peak (b) and $\mathrm{S} 2 \mathrm{p}$ peak (c) in $\mathrm{PMO}-\mathrm{SO}_{3} \mathrm{H}_{2} \mathrm{SiO}_{2}-\mathrm{NH}_{2}$. Insert in Figure 5c: curves fitting of $\mathrm{S} 2 \mathrm{p}$ peak in $\mathrm{PMO}-\mathrm{SH} \& \mathrm{SiO}_{2}-\mathrm{NH}_{2}$. Curves fitting of N1s peak in $\mathrm{PMO}-\mathrm{SO}_{3} \mathrm{H} \& \mathrm{SiO}_{2}-\mathrm{NR}$ (d). 
spectrum of $\mathrm{PMO}-\mathrm{SO}_{3} \mathrm{H} \& \mathrm{SiO}_{2}-\mathrm{NR}$ showed a new characteristic absorption at $1680 \mathrm{~cm}^{-1}(\sigma(\mathrm{C}=\mathrm{O})$ in amide group) and the significant absorption enhancement at $2930 \mathrm{~cm}^{-1}(\sigma(\mathrm{C}-\mathrm{H}))[32,33]$, indicating the successful grafting of palmitoyl chloride on porous Janus $\mathrm{PMO}-\mathrm{SO}_{3} \mathrm{H} \& \mathrm{SiO}_{2}-\mathrm{NH}_{2}$ nanoparticle. Further, TGA curves (Figure 4b) were utilized to quantitatively characterize the actual grafting amount of Janus nanoparticles. As can be seen, the residues at $800{ }^{\circ} \mathrm{C}$ in $\mathrm{N}_{2}$ atomosphere were $81.39 \%$ for $\mathrm{PMO} \& \mathrm{SiO}_{2}, 78.48 \%$ for $\mathrm{PMO}-\mathrm{SO}_{3} \mathrm{H} \& \mathrm{SiO}_{2}-\mathrm{NH}_{2}$ and $76.05 \%$ for $\mathrm{PMO}-\mathrm{SO}_{3} \mathrm{H} \& \mathrm{SiO}_{2}-\mathrm{NR}$. This indicated that the graft amount was $0.029 \mathrm{~g}$ (APTES and MPTMS)/g ( $\left.\mathrm{SiO}_{2} @ \mathrm{PMO}\right)$ and $0.024 \mathrm{~g}$ (palmitoyl chloride)/g $\left(\mathrm{SiO}_{2}-\mathrm{SO}_{3} \mathrm{H} @ \mathrm{PMO}-\mathrm{NH}_{2}\right)$.

Figure 5a presents XPS wide-scan spectra of porous Janus $\mathrm{PMO}_{2} \mathrm{SiO}_{2}, \mathrm{PMO}-\mathrm{SO}_{3} \mathrm{H} \& \mathrm{SiO}_{2}-\mathrm{NH}_{2}$, and $\mathrm{PMO}-\mathrm{SO}_{3} \mathrm{H} \& \mathrm{SiO}_{2}-\mathrm{NR}$ nanoparticles. It can be seen that three porous Janus nanoparticles all possessed the peaks of O1s (532 eV), C1s (284 eV), Si2s (120 eV) and $\mathrm{Si} 2 \mathrm{p}(102 \mathrm{eV})$, consistent with the reported ones $[17,34]$. The difference was that the spectra of $\mathrm{PMO}-\mathrm{SO}_{3} \mathrm{H} \& \mathrm{SiO}_{2}-\mathrm{NH}_{2}$ and $\mathrm{PMO}-\mathrm{SO}_{3} \mathrm{H} \& \mathrm{SiO}_{2}-\mathrm{NR}$ showed the new peaks of N1s and S2p in comparison with that of $\mathrm{PMO}_{2} \mathrm{SiO}_{2}$. In detail, N1s peak of $\mathrm{PMO}-\mathrm{SO}_{3} \mathrm{H} \& \mathrm{SiO}_{2}-\mathrm{NH}_{2}$ appeared at $399.5 \mathrm{eV}(\mathrm{N}-\mathrm{H}$, Figure $5 b$ ), and the peak of $\mathrm{S} 2 \mathrm{p}$ was divided into two peaks with $169.2 \mathrm{eV}(\mathrm{S}-\mathrm{O})$ and $168.0 \mathrm{eV}(\mathrm{S}=\mathrm{O})$ (Figure 5c), suggesting the existence of $-\mathrm{NH}_{2}$ on $\mathrm{SiO}_{2}$ branches and $-\mathrm{SO}_{3} \mathrm{H}$ on $\mathrm{PMO}$ cores, respectively. Notably, in the insert picture of Figure $5 \mathrm{c}$, the fitting peak of S2p of PMO-SH\&SiO $2-\mathrm{NH}_{2}$ was $164.0 \mathrm{eV}$ $(-\mathrm{SH})$, whereas this peak disappeared in Figure $5 \mathrm{c}$. This demonstrated that -SH in (3-mercaptopropyl)trimethoxysilane residues had been thoroughly oxidized into $-\mathrm{SO}_{3} \mathrm{H}$. Besides, the fitting curve of N1s of $\mathrm{PMO}-\mathrm{SO}_{3} \mathrm{H} \& \mathrm{SiO}_{2}-\mathrm{NR}$ showed a new peak at $401.6 \mathrm{eV}(\mathrm{O}=\mathrm{C}-\mathrm{N})$ (Figure $5 \mathrm{~d})$ in addition to the fitting peak at $399.5 \mathrm{eV}(\mathrm{N}-\mathrm{H})$, indicating the existence of amide bond [35]. This further proved the successful preparation of porous Janus $\mathrm{PMO}-\mathrm{SO}_{3} \mathrm{H}_{2} \mathrm{SiO}_{2}-$ NR nanoparticle.

Figure 6 show the $\mathrm{N}_{2}$ adsorption-desorption isotherms and pore size distribution of porous Janus $\mathrm{PMO} \& \mathrm{SiO}_{2}$ and $\mathrm{PMO}-\mathrm{SO}_{3} \mathrm{H} \& \mathrm{SiO}_{2}-\mathrm{NR}$ nanoparticles, respectively. The nitrogen adsorption-desorption isotherms of the synthesized nanoparticles exhibited type-IV hysteresis, indicative the presence of mesopores [29]. The BET surface areas were calculated to be $606 \mathrm{~m}^{2} \cdot \mathrm{g}^{-1}$ for $\mathrm{PMO} \& \mathrm{SiO}_{2}$ and $420 \mathrm{~m}^{2} \cdot \mathrm{g}^{-1}$ for $\mathrm{PMO}-\mathrm{SO}_{3} \mathrm{H} \& \mathrm{SiO}_{2}-\mathrm{NR}$, respectively. The relatively lower specific surface area of $\mathrm{PMO}-\mathrm{SO}_{3} \mathrm{H} \& \mathrm{SiO}_{2}-$ NR may be attributed that the introduction of hexa-

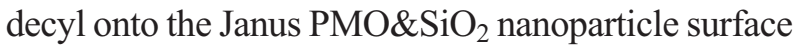
blocked part of the pores [19]. Even so, it was much larger than those of most nanomaterials $[12,36]$. Besides, Janus $\mathrm{PMO}_{2} \mathrm{SiO}_{2}$ and $\mathrm{PMO}-\mathrm{SO}_{3} \mathrm{H} \& \mathrm{SiO}_{2}-\mathrm{NR}$ nanoparticles showed the similar pore diameter near 1.40 and $2.75 \mathrm{~nm}$ (Figure 6b), which was consistent with the Janus structure of nanoparticles synthesized by the sprout-like growth method. The pore diameter of Janus nanoparticles was much larger than the size of water molecule $(0.28 \mathrm{~nm})$, probably providing additional passways for water in the water treatment process [36].

Moreover, the microstructures of the porous Janus nanoparticles were performed by SEM. As shown in Figure 7, porous Janus $\mathrm{PMO} \& \mathrm{SiO}_{2}$ and $\mathrm{PMO}-\mathrm{SO}_{3} \mathrm{H} \&$ $\mathrm{SiO}_{2}$-NR nanoparticles had the similar morphology and size composed of core (diameter: $\sim 120 \mathrm{~nm}$ ) and branch (diameter: $\sim 60 \mathrm{~nm}$ ) as well as the total length

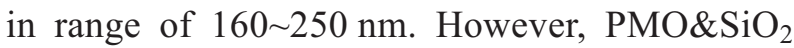

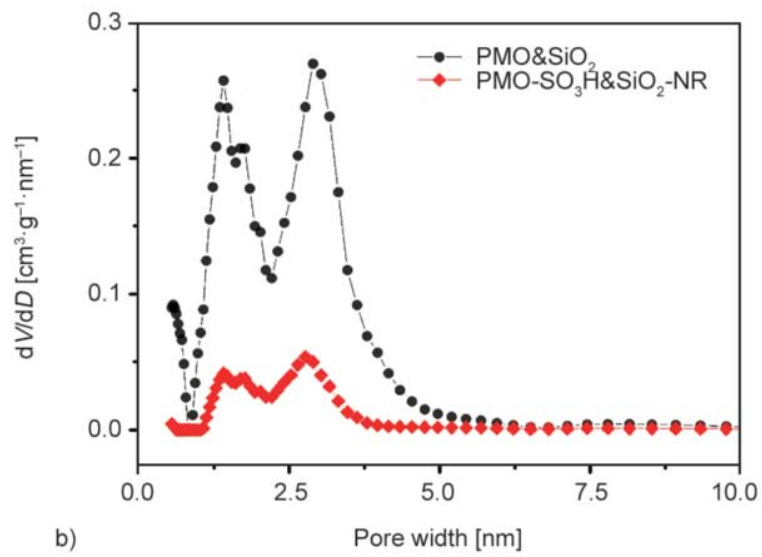

Figure 6. $\mathrm{N}_{2}$ adsorption-desorption isotherms (a) and pore-size distribution (b) of porous Janus $\mathrm{PMO}_{2} \mathrm{SiO}_{2}$ and $\mathrm{PMO}-$ $\mathrm{SO}_{3} \mathrm{H} \& \mathrm{SiO}_{2}-\mathrm{NR}$ nanoparticles. 


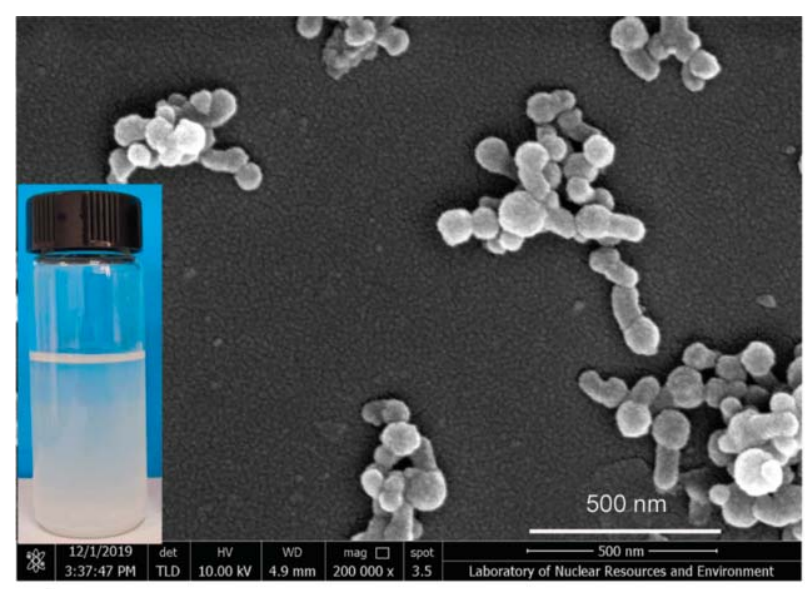

a)

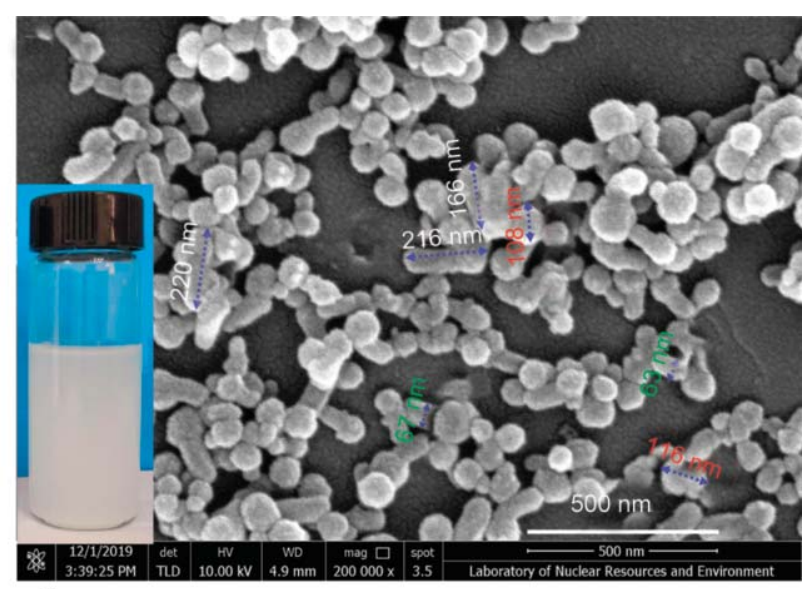

b)

Figure 7. SEM images of porous Janus nanoparticles: $\mathrm{PMO}_{\mathrm{SSiO}}(\mathrm{a}) ; \mathrm{PMO}-\mathrm{SO}_{3} \mathrm{H} \& \mathrm{SiO}_{2}-\mathrm{NR}(\mathrm{b})$. Inset: pictures of corresponding porous Janus nanoparticles dispersed in DMF for two weeks.

showed obvious agglomeration in comparison with $\mathrm{PMO}-\mathrm{SO}_{3} \mathrm{H} \& \mathrm{SiO}_{2}-\mathrm{NR}$, which was also confirmed by their dispersibility in DMF. The mixture containing $\mathrm{PMO} \& \mathrm{SiO}_{2}$ showed serious stratification after standing for two weeks (Figure 7a insert), while $\mathrm{PMO}-\mathrm{SO}_{3} \mathrm{H} \& \mathrm{SiO}_{2}-\mathrm{NR}$ was still uniformly dispersed in DMF (Figure 7b insert) due to the strong interaction between hexadecyl and DMF. The good dispersibility of porous Janus $\mathrm{PMO}-\mathrm{SO}_{3} \mathrm{H} \& \mathrm{SiO}_{2}-\mathrm{NR}$ nanoparticles was very advantageous for improving their compatibility with PES membrane matrix and the preparation of defect-free UF membrane.

\subsection{Morphologies of the mixed matrix membranes}

The morphology of the UF membrane plays a crucial role in the water flux and rejection. To fully study the effect of porous Janus nanoparticles on the membrane structure, SEM images of the surface and crosssection of mixed matrix membranes were shown in Figure 8. All the membranes exhibited a typical asymmetric membrane structure consisting of a dense skin layer and a porous support layer. Versus pristine PES membrane (M0), the mixed matrix membranes (M1, M3, M5, M3') possessed the longer and wider finger-like structure. This can be ascribed that the increased thermodynamic instability of the casting solution generated by the incorporation of porous Janus nanoparticles as well as the hydrophilic $-\mathrm{SO}_{3} \mathrm{H}$ and $-\mathrm{OH}$ of Janus nanoparticles jointly promoted the exchange rate between solvent (DMF) and non-solvent (water), resulting in the presence of an instantaneous phase separation and hence the formation of a very porous structure [37]. Besides, with the increased addition of porous Janus PMO$\mathrm{SO}_{3} \mathrm{H} \& \mathrm{SiO}_{2}-\mathrm{NR}$ nanoparticles, the skin thickness decreased from $1.2 \mu \mathrm{m}$ of M0 to $1.0 \mu \mathrm{m}$ of $\mathrm{M} 1$ and $0.5 \mu \mathrm{m}$ of M3 (Table 2), which can be interpreted by the instantaneous phase separation contributing to the formation of a thinner skin layer. Among all the mixed matrix membranes, M3 owned the thinnest skin layer thickness and the largest surface mean pore size $(8.5 \mathrm{~nm}$, Table 2$)$. This was attributed to the relatively large amounts of porous Janus PMO$\mathrm{SO}_{3} \mathrm{H} \& \mathrm{SiO}_{2}$-NR nanoparticles and abundantly hydrophilic $-\mathrm{SO}_{3} \mathrm{H}$. However, further increasing porous Janus PMO-SO)H\& $\mathrm{SiO}_{2}$-NR nanoparticles to $5 \mathrm{wt} \%$ led to the significantly reduced pore size $(7.8 \mathrm{~nm}$, Table 2) and the increased thickness of skin layer $(0.7 \mu \mathrm{m}$, Table 2$)$. This can be attributed to the fact that the blending of $5 \mathrm{wt} \%$ nanoparticles remarkably enhanced the viscosity of the casting solution and thus decelerated the exchange rate of the solvent and non-solvent, leading to the delayed phase separation and hence the formation of dense and thick skin layer [38]. Thus, in this study, the maximum addition of porous Janus nanoparticles was $5 \mathrm{wt} \%$.

Moreover, the distribution of porous Janus nanoparticles on the membrane surface was shown in Figure $8 \mathrm{c}$, and the partially enlarged top surface of membrane without obvious protruding area and the pore size distribution were presented in Figure 8d. M0 without Janus nanoparticles had a relatively smooth and dense surface. With the increased addition of porous Janus $\mathrm{PMO}-\mathrm{SO}_{3} \mathrm{H} \& \mathrm{SiO}_{2}-\mathrm{NR}$ nanoparticles, the number of nanoparticles that spontaneously migrated to the membrane surface gradually increased, and they were all uniformly distributed close to the 


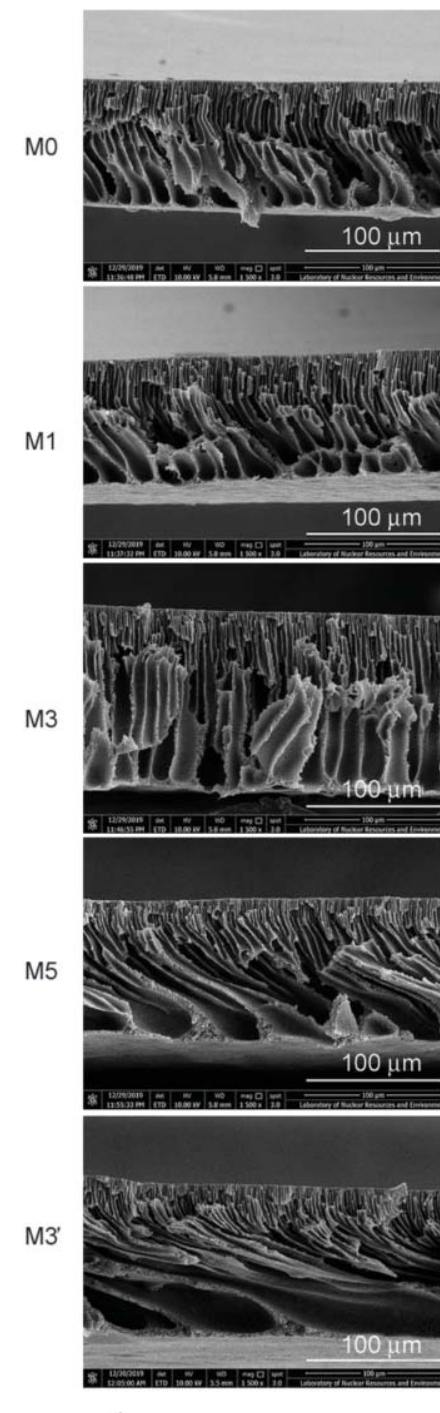

a)
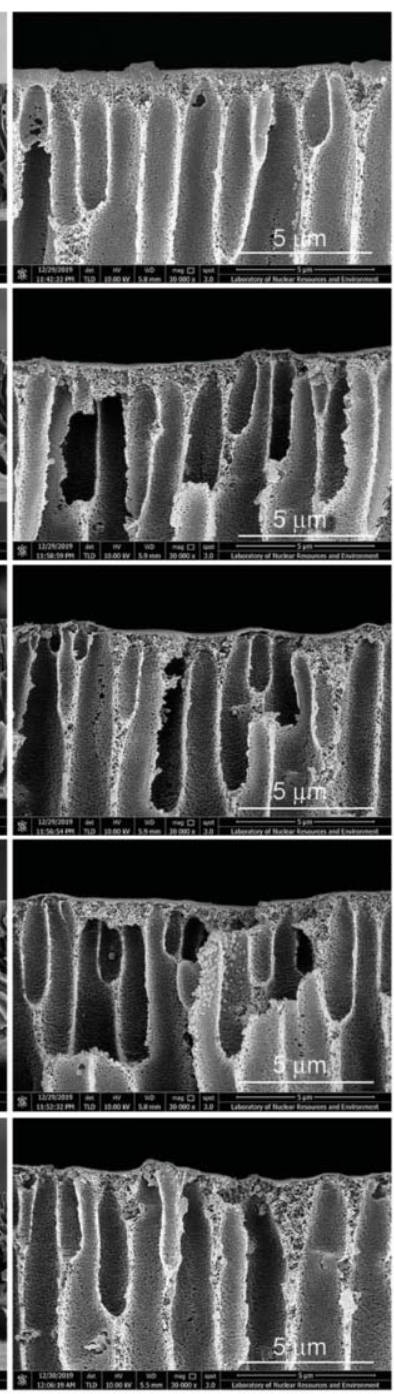

b)

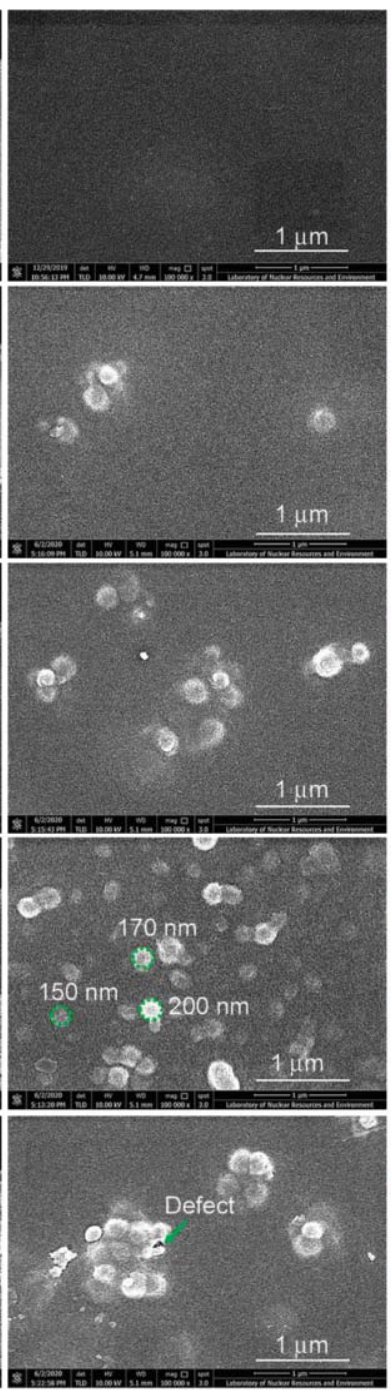

c)
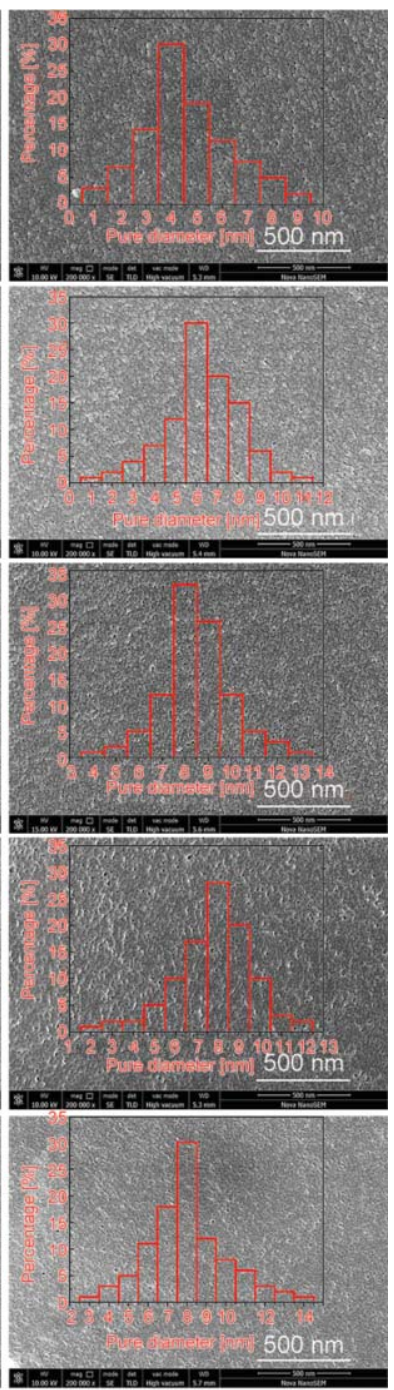

d)

Figure 8. Morographies of the mixed matrix membranes. The four vertical rows corresponded to cross-section SEM images (a) (1500×); Partially enlarged view of the skin layer (b) (30000×); Top surface SEM images (c) (100 000×); Partially enlarged top surface SEM images (d) $(200000 \times)$ and the corresponding pore size distribution.

skin layer. However, for M3'with $3 \mathrm{wt} \%$ porous Janus $\mathrm{PMO}_{\mathrm{SiO}}$ nanoparticles, the nanoparticles that migrated to the membrane surface showed an obvious agglomeration accompanied by the protruding of some nanoparticles derived from the excessive migration, resulting in the non-selective defects on the surface of the membrane. This was mainly because porous Janus $\mathrm{PMO}-\mathrm{SO}_{3} \mathrm{H} \& \mathrm{SiO}_{2}$-NR nanoparticles had the long and flexible organic chain that enhanced the dispersibility of nanoparticles themselves and their compatibility with PES membrane matrix, resulting in porous Janus $\mathrm{PMO}-\mathrm{SO}_{3} \mathrm{H} \& \mathrm{SiO}_{2}$-NR nanoparticles moderately migrating close to skin layer in comparison with porous Janus $\mathrm{PMO} \& \mathrm{SiO}_{2}$ nanoparticles during membrane preparation. It was worth noting that the size of porous Janus $\mathrm{PMO}-\mathrm{SO}_{3} \mathrm{H} \& \mathrm{SiO}_{2}-\mathrm{NR}$ nanoparticles distributed close to the skin layer was in range of 150 200 $\mathrm{nm}$ that more similar to the diameter of the PMO cores, indicating the hydrophilic $\mathrm{PMO}-\mathrm{SO}_{3} \mathrm{H}$ cores directionally migrating to the membrane surface and the hydrophobic $\mathrm{SiO}_{2}$-NR branches binding firmly to the PES matrix. This point can be further confirmed by the distribution of Janus nanoparticles in the finger-like sub-layer, as shown in Figure 9. In detail, the agglomerated porous Janus $\mathrm{PMO}_{2} \mathrm{SiO}_{2}$ nanoparticles were nondirectionally distributed in the finger-like structure of M3' (Figure 9b), while the porous Janus PMO- $\mathrm{SO}_{3} \mathrm{H} \& \mathrm{SiO}_{2}-\mathrm{NR}$ nanoparticles were directionally and uniformly embedded in the finger-like structure of M3 (Figure 9a) with $\mathrm{SiO}_{2}-\mathrm{NR}$ branches inserting the membrane matrix and the $\mathrm{PMO}-\mathrm{SO}_{3} \mathrm{H}$ cores exposing on the membrane matrix. Moreover, the EDX mapping of silicon element in Figure $9 \mathrm{c}$ was consistent with the distribution 


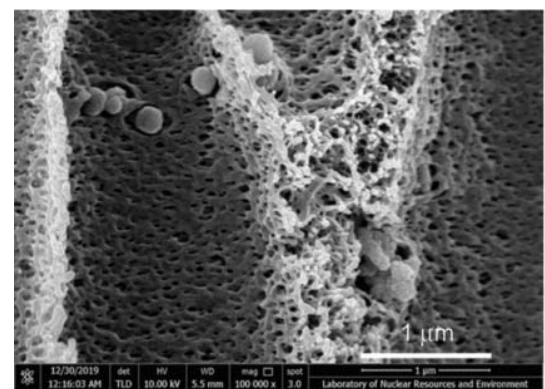

a)

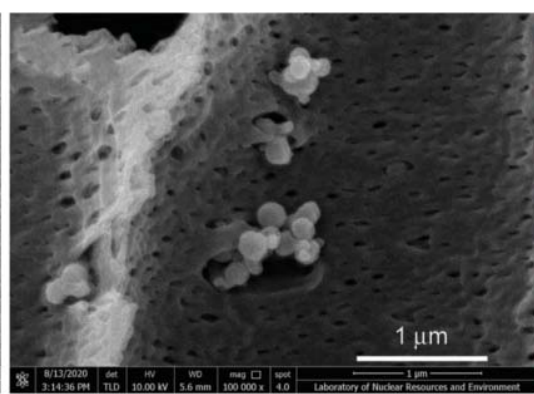

b)

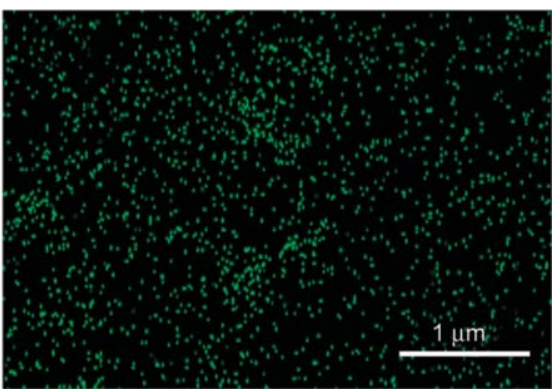

Si $K \alpha 1$

Figure 9. Cross-section SEM images $(100000 \times)$ of the finger-like sub-layer of M3 (a) and M3' (b). EDX mapping of silica element on the surface M3' (c).

of Janus $\mathrm{PMO} \& \mathrm{SiO}_{2}$ nanoparticles in Figure $9 \mathrm{~b}$. However, the size of the nanoparticles distributed close to the skin layer was slightly larger than that of nanoparticles in Figure $7 \mathrm{~b}$. This was likely due to the inhomogeneity of nanoparticle size as well as part of the nanoparticle surface coated by PES in membrane matrix [39].

The AFM images and roughness parameters $\left(R_{\mathrm{a}}\right.$ and $R_{\mathrm{q}}$ ) of all the mixed matrix membrane surfaces were depicted in Figure 10 and Table 2, respectively. It was worth noting that except M3', the changes in the surface roughness were positively correlated with the changes in the bulk porosity and the surface mean pore size (Table 2). In other words, membranes with a higher porosity and a larger average pore size owned greater roughness, which was in line with other reports $[12,40]$. Intriguingly, M3' performed unusual surface roughness up to $44.92 \mathrm{~nm}$ in spite of its surface mean pore size and porosity having no obvious changes. This may be attributed that the poor compatibility between $\mathrm{PMO}_{\mathrm{SiO}}$ and PES matrix destabilized the Janus nanoparticles in the casting solution, resulting in the excessive migration of the $\mathrm{PMO} \& \mathrm{SiO}_{2}$ to the membrane surface in phase separation process [17]. The porous Janus $\mathrm{PMO} \& \mathrm{SiO}_{2}$ nanoparticles that outwardly bulged from the membrane surface will undoubtedly lead to a considerable increase in the surface roughness, which was consistent with the SEM results in Figure 8c.

Table 2. Structure parameters of the mixed matrix membranes.

\begin{tabular}{|c|c|c|c|c|c|c|}
\hline \multirow[b]{2}{*}{ Membrane } & \multirow[b]{2}{*}{$\begin{array}{c}\text { Thickness } \\
{[\mu \mathrm{m}]}\end{array}$} & \multirow{2}{*}{$\begin{array}{c}\text { Skin thickness } \\
{[\mu \mathrm{m}]}\end{array}$} & \multirow{2}{*}{$\begin{array}{c}\text { Bulk porosity } \\
{[\%]}\end{array}$} & \multirow[b]{2}{*}{$\begin{array}{c}\text { Surface mean pore size } \\
\text { [nm] }\end{array}$} & \multicolumn{2}{|c|}{ Roughness } \\
\hline & & & & & $\begin{array}{c}R_{\mathrm{a}} \\
{[\mathrm{nm}]}\end{array}$ & $\begin{array}{c}R_{\mathrm{q}} \\
{[\mathrm{nm}]}\end{array}$ \\
\hline M0 & $97 \pm 3.2$ & $1.2 \pm 0.3$ & $73 \pm 2.5$ & $4.6 \pm 0.3$ & 8.95 & 10.37 \\
\hline M1 & $91 \pm 2.0$ & $1.0 \pm 0.2$ & $76 \pm 3.0$ & $6.3 \pm 0.9$ & 13.45 & 18.65 \\
\hline M3 & $128 \pm 1.8$ & $0.5 \pm 0.2$ & $81 \pm 2.8$ & $8.5 \pm 1.0$ & 22.22 & 26.32 \\
\hline M5 & $106 \pm 0.9$ & $0.7 \pm 0.1$ & $79 \pm 1.7$ & $7.8 \pm 0.7$ & 19.71 & 22.95 \\
\hline M3' & $110 \pm 1.6$ & $0.6 \pm 0.3$ & $81 \pm 3.2$ & $8.0 \pm 0.5$ & 44.92 & 53.64 \\
\hline
\end{tabular}

$R_{\mathrm{a}}$, the average roughness; $R_{\mathrm{q}}$, root mean square roughness.
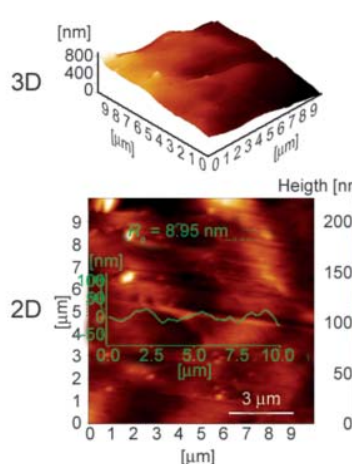

MO
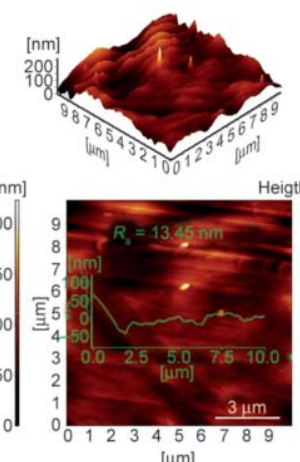

M1
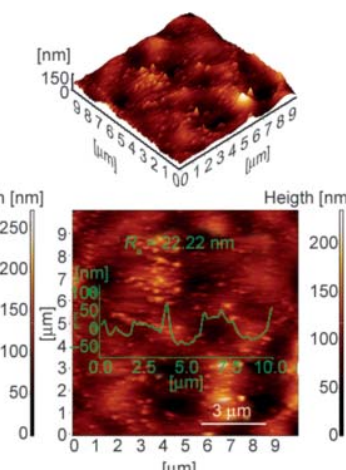

[um]
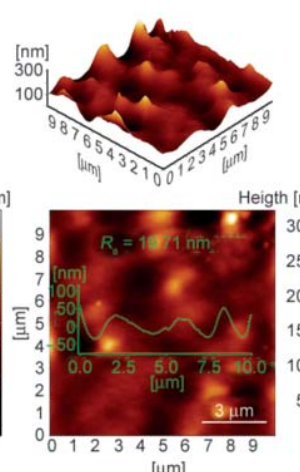

M5
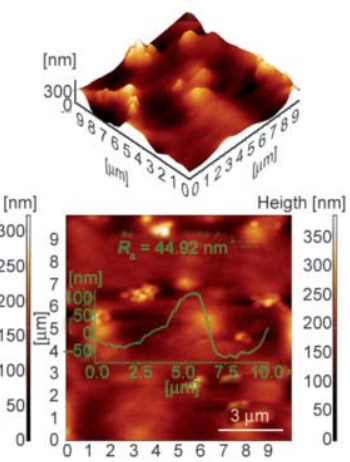

[ $\mu \mathrm{m}]$

M3'

Figure 10. 3D and 2D AFM images of the mixed matrix membranes. 


\subsection{Hydrophilicity and porosity of the mixed matrix membranes}

The hydrophilicity of the membrane is of paramount importance to its permeation flux as well as the antifouling performance. Generally, the more hydrophilic the membrane is, the easier it is for water molecules to permeate the membrane matrix, and the membrane surface is less likely to be contaminated [12]. In this study, water contact angle was utilized to evaluate the hydrophilicity of the mixed matrix membranes. As shown in Figure 11, water contact angles of the membranes presented in the order of M5 $<$ M $3^{\prime}<\mathrm{M} 3<\mathrm{M} 1<\mathrm{M} 0$. The pristine PES membrane (M0) exhibited the maximum contact angle of $80^{\circ}$, suggesting the hydrophobicity nature of PES matrix. Moreover, with the increased addition of the porous Janus $\mathrm{PMO}-\mathrm{SO}_{3} \mathrm{H} \& \mathrm{SiO}_{2}-\mathrm{NR}$ nanoparticles, the contact angles of the membranes progressively decreased, and hence M5 exhibted the minimum water contact angle of $56^{\circ}$. This was mainly because the abundant $\mathrm{PMO}-\mathrm{SO}_{3} \mathrm{H}$ cores can directionally migrate to the membrane surface and improve the hydrophilicity of the PES UF membrane. The larger the addition of porous Janus PMO- $\mathrm{SO}_{3} \mathrm{H} \& \mathrm{SiO}_{2}-\mathrm{NR}$ nanoparticles, the more hydrophilic $-\mathrm{SO}_{3} \mathrm{H}$ on the membrane surface, and the stronger hydrophilicity of the membrane. However, versus M3 $\left(60^{\circ}\right), \mathrm{M}^{\prime}$ $\left(58^{\circ}\right)$ showed a slightly reduced water contact angle though $\mathrm{M} 3$ having the more $-\mathrm{SO}_{3} \mathrm{H}$ on the membrane surface. This was mainly attributed that the larger roughness and the non-selective defects of M3 surface contributed to the penetration and spread of water droplets on the membrane surface.

Meanwhile, the bulk porosity of the mixed matrix membranes was also summarized in Table 2, which was closely related to the permeation flux. Versus the pristine PES membrane (M0), the mixed matrix membranes with porous Janus nanoparticles (M1, $\mathrm{M} 3$, M5, and M3') showed markedly increased porosity due to the porous Janus nanoparticles, the formation of tiny interface voids between the Janus nanoparticles and the membrane matrix, and the porous membrane matrix resulted from an instantaneous phase separation. Besides, it can be found that the bulk porosity of the membranes increased first and then slightly decreased with the increased addition of porous Janus PMO-SO3H\&SiO2-NR nanoparticles. This was mainly because the hydrophilicity and viscosity had different effects on the kinetics and thermodynamic behavior of the membrane preparation

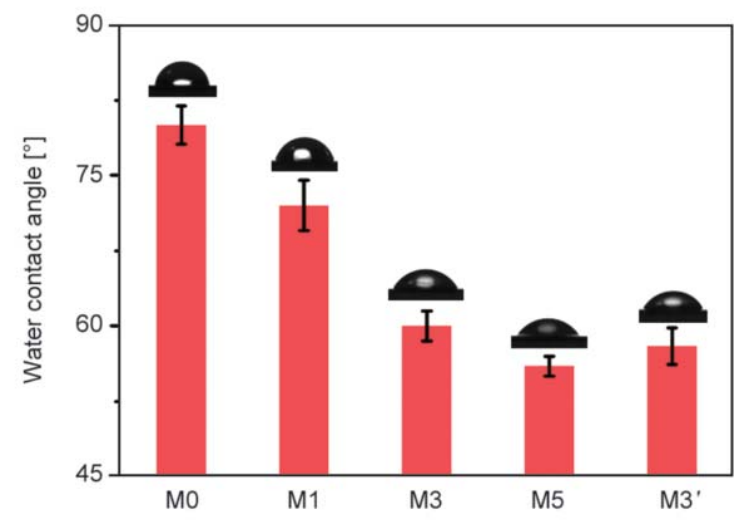

Figure 11. Water contact angles of the mixed matrix membranes.

process [41]. The increased hydrophilicity tended to result in the appearance of instantaneous phase separation contributing to the formation of porous structure, which played a greater role in determining the membrane porosity than did the viscosity as the addition of porous Janus nanoparticles was less than $3 \mathrm{wt} \%$; while apparent increase in viscosity caused the occurrence of the delayed phase separation leading to the formation of a dense structure, which was dominant in determining the membrane porosity as the addition of porous Janus nanoparticles reached $5 \mathrm{wt} \%$. Overall, the addition of porous Janus nanoparticles enhanced the bulk porosity of PES UF membrane, which was very beneficial for the improvement of the permeation flux.

\subsection{Permeability, rejection and antifouling performance of the mixed matrix membranes}

Ultrafiltration experiment was used to evaluate the permeability, rejection and antifouling performance of the membrane. Figure 12a shows the the flux-time curves of the mixed matrix membranes in the first cycle with BSA as model contaminant. Based on the data in Figure 12a, the pure water fluxes and the BSA rejections of the mixed matrix membranes were summarized and shown in Figure 12b. With the increased addition of porous Janus nanoparticles, the pure water fluxes of the membranes increased from $150 \mathrm{l} \cdot \mathrm{m}^{-2} \cdot \mathrm{h}^{-1}$ of $\mathrm{M} 0,255 \mathrm{l} \cdot \mathrm{m}^{-2} \cdot \mathrm{h}^{-1}$ of $\mathrm{M} 1$, $353 \mathrm{l} \cdot \mathrm{m}^{-2} \cdot \mathrm{h}^{-1}$ of M3 to $330 \mathrm{l} \cdot \mathrm{m}^{-2} \cdot \mathrm{h}^{-1}$ of M5 and $395 \mathrm{l} \cdot \mathrm{m}^{-2} \cdot \mathrm{h}^{-1}$ of $\mathrm{M}^{\prime}$, and the correspongding rejections for BSA all maintained at above $98.0 \%$ except for M3' $(92.0 \%)$. The addition of porous Janus nanoparticles siginificantly enhanced the water flux of PES UF membrane, especially, the pure water flux 
of M3 was nearly 2.4 times that of the pristine PES membrane (M0). This was primarily due to the synergistic effects of the increased surface pore size, bulk porosity, hydrophilicity as well as the thinning of skin layer. These were very conducive for water molecules to permeate through the membrane matrix. Meanwhile, although M5 had a more hydrophilic surface, the pure water flux of M5 was slightly lower than that of M3. This was mainly owing to the decreased bluk porosity and surface pore size caused by the delayed phase separation as the addition of porous Janus nanoparticles reaching $5 \mathrm{wt} \%$. In this case, porosity and pore size played the greater role in determining the water flux than hydrophilicity. Besides, versus M0, there was no significant attenuation in rejection as porous Janus $\mathrm{PMO}-\mathrm{SO}_{3} \mathrm{H} \&$ $\mathrm{SiO}_{2}-\mathrm{NR}$ nanoparticle acted as blending filler. This was mainly attributed to two aspects: (1) the occurance of the delayed phase separation as well as the excellent compatibility between porous Janus PMO$\mathrm{SO}_{3} \mathrm{H} \& \mathrm{SiO}_{2}$-NR nanoparticles and PES polymer membrane matrix resulted in the appropriate pore size; (2) the hydrophilic membrane can form the hydration layer on the membrane surface that will exclude hydrophobic protein to reduce the amount of protein penetrating through the UF membrane and thus maintain rejection constant. Overall, the mixed matrix membranes with porous Janus $\mathrm{PMO}-\mathrm{SO}_{3} \mathrm{H} \&$ $\mathrm{SiO}_{2}$-NR obtained the improved water flux while maintained a high BSA rejection, which was very important for the efficiency and quality of water treatment. Unfortunately, M3' obtained the maximum water flux at the expense of the rejection due to the non-selective defects casued by the easily agglomerated porous Janus PMO\& $\mathrm{SiO}_{2}$ nanoparticles as well as their excessive migration resulted from the inferior compatibility with PES membrane matrix. Obviously, M3' can not meet the requirements of water treatment for UF membrane.

The antifouling performance of the UF membrane has close relationships with the efficiency of water treatment, the membrane lifespan as well as the production costs. It is generally accepted that the chemical composition and roughness of the membrane surface are responsible for antifouling performance of the membrane [18]. Herein, the first cycle UF experiment parameters including $J_{\mathrm{w} 1}, J_{\mathrm{p} 1}, J_{\mathrm{w} 2}$ was utilized to calculate $R_{\mathrm{t}}, R_{\mathrm{r}}, R_{\mathrm{ir}}$ and ${ }_{\mathrm{FRR}}$ to assess the
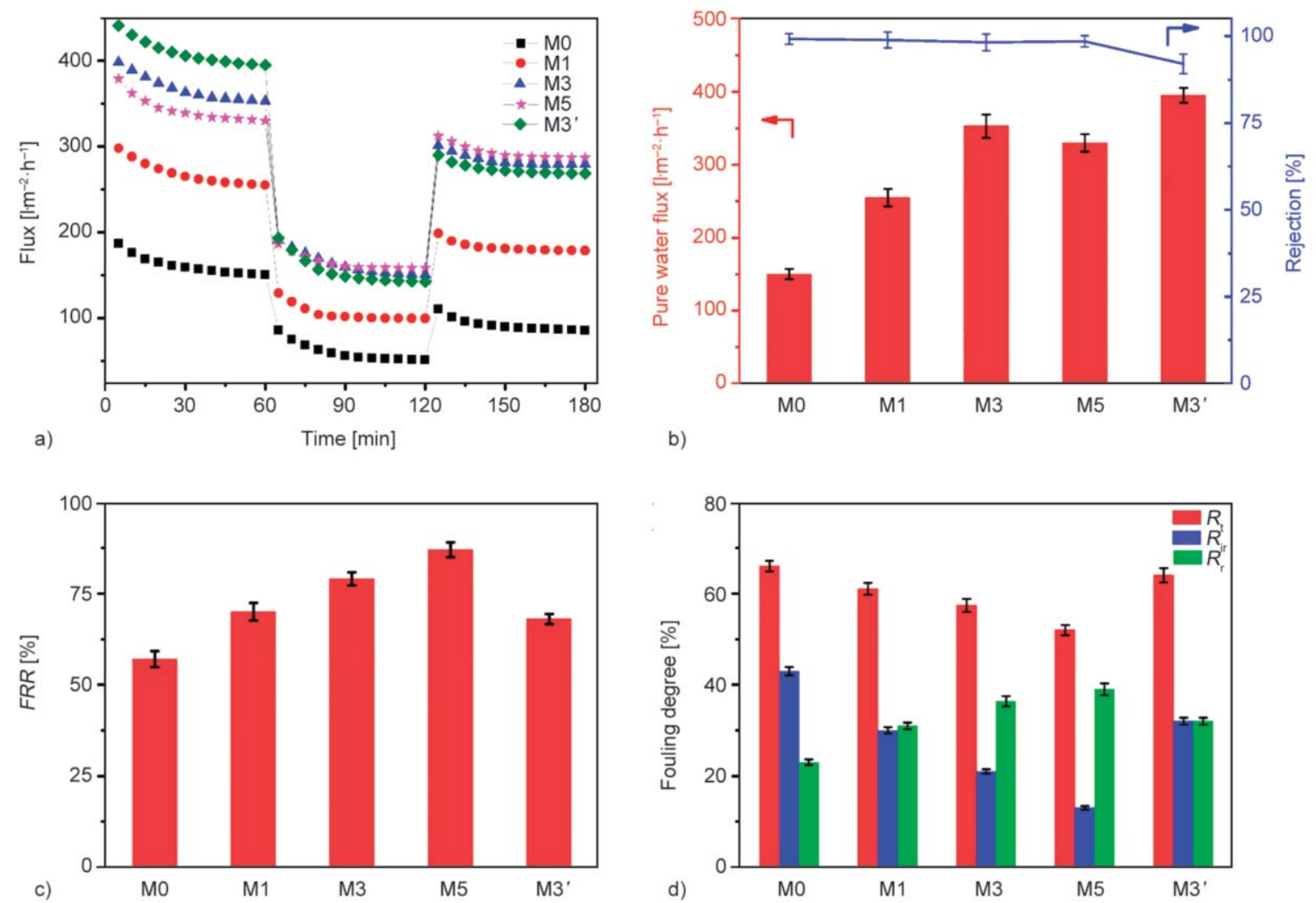

Figure 12. Flux-time curves with BSA as model contaminant (a), the fluxes and rejections (b), the $F R R$ (c), and fouling degree (d) of the mixed matrix membranes in the first cycle. 
antifouling performance of the mixed matrix membranes from various aspects. As shown in Figure 12a, when the feed solution was changed from pure water to BSA solution, the permeation flux sharply dropped, mainly due to BSA molecules blocking the membrane pore or depositing on the membrane surface to form a fouling layer; subsequently, the water fluxes of the mixed matrix membranes recovered in different degrees after being cleaned by pure water. Specifically, the FRR increased from $57 \%$ of M0, $70 \%$ of M1 to $79 \%$ of M3, $87 \%$ of M 5 and $68 \%$ of M3' (Figure 12c), the corresponding $R_{\mathrm{t}}$ dropped from $66 \%$ of M0, $61 \%$ of M1 to $57 \%$ of M3, $52 \%$ of M5 and 64\% of M3' (Figure 12d). The FRR of M1, M3, M5 were far higher than those of M0 and M3', especially, M5 owned the lowest $R_{\text {ir }}$ of $13 \%$, indicating the best antifouling performance. This was mainly because the $\mathrm{PMO}-\mathrm{SO}_{3} \mathrm{H}$ core of porous Janus $\mathrm{PMO}-\mathrm{SO}_{3} \mathrm{H} \& \mathrm{SiO}_{2}-\mathrm{NR}$ nanoparticle can directionally migrate to the membrane surface and abundant $-\mathrm{SO}_{3} \mathrm{H}$ will markedly enhance the membrane hydrophilicity forming a hydration layer on the membrane surface via hydrogen bonding, which can effectively impede the adhesion of contaminants and further facilitate membrane cleaning [30]. However, for $\mathrm{M}^{\prime}$ ' with porous Janus $\mathrm{PMO} \& \mathrm{SiO}_{2}$ nanoparticle, it showed a larger flux attenuation and a lower flux recovery compared with other mixed matrix membranes (M1, M3, and M5) (Figure 12a), consequent$1 y$, its antifouling performance was not distinctly improved in comparison with the pristine PES membrane. This was mainly ascribed to the relatively weak hydrophilicity and the larger roughness of M3', resuting in the BSA easily sticking on the membrane surface and hard to be cleaned off [42].

\subsection{Long-term performance stability of the mixed matrix membranes}

The long-term performance stability of UF membrane is an important prerequisite for continuous industrial water treatment. In this study, M5 with excellent comprehensive performance was selected to investigate its long-term performance stability. Firstly, we conducted a test on M5 with pure water at $0.1 \mathrm{MPa}$ for a week, and the result was shown in Figure 13a. It can be found that the pure water flux of
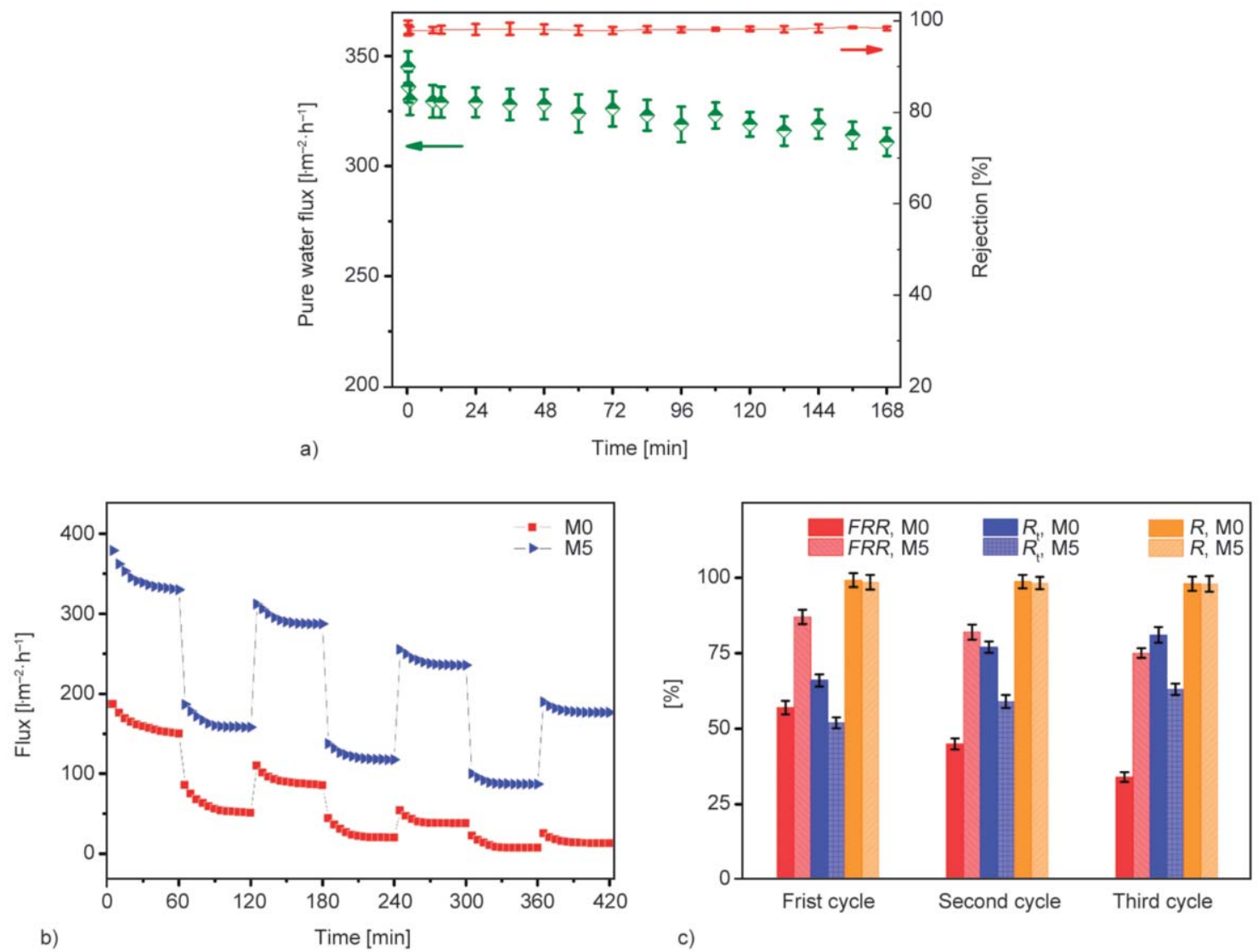

Figure 13. Pure water fluxes of M5 for a week in UF experiment (a). The flux-time curves (b) and $F R R, R_{\mathrm{t}}$, and $R$ (c) of M0 and M5 in three cycles of UF experiments. 
M5 declined slightly at the initial stage and then stabilized near $3111 \cdot \mathrm{m}^{-2} \cdot \mathrm{h}^{-1}$, and less than $6 \%$ flux decline was observed after $168 \mathrm{~h}$, and the rejection is greater than $98 \%$. This demonstrated M5 possessed good operation stability in the process of water treatment. Moreover, in order to truly reflect the longterm performance stability of M5 in the actual water treatment process, $\mathrm{M} 0$ and $\mathrm{M} 5$ were selected for the three cycles of UF experiment using BSA as the model contaminant. Their flux-time curves and the parameters including $F R R, R_{\mathrm{t}}, R$ were shown in Figure $13 \mathrm{~b}$ and $13 \mathrm{c}$, respectively. With the increased cycles of UF experiment, the rejections for BSA of M0 and M5 basically remained above $98 \%$ while their $F R R$ and $R_{\mathrm{t}}$ gradually decreased and increased, respectively. This was mainly because the residual BSA on the membrane surface was easy to absorb more BSA molecules due to the electrostatic force between BSA molecules, which was consistent with other reports $[43,44]$. Interestingly, after three cycles, the performance of $\mathrm{M} 0$ deteriorated seriously, for example, the water flux was only $12 \mathrm{l} \cdot \mathrm{m}^{-2} \cdot \mathrm{h}^{-1}$, while M5 can still maintain a high water flux $\left(177 \mathrm{l} \cdot \mathrm{m}^{-2} \cdot \mathrm{h}^{-1}\right)$, stable rejection (97.9\%) and good antifouling performance (FRR, 75\%), indicating excellent long-term performance stability. In general, as a novel additive, porous Janus $\mathrm{PMO}-\mathrm{SO}_{3} \mathrm{H} \& \mathrm{SiO}_{2}$-NR nanoparticle successfully improve the comprehensive performance of PES UF membrane.

To compare the filtration performance of UF membranes in permeation flux and BSA rejection, Figure 14 summarizes a comparison of some prepared composite UF membranes in literatures to M5 in this study. It was worth noting that the pure water flux

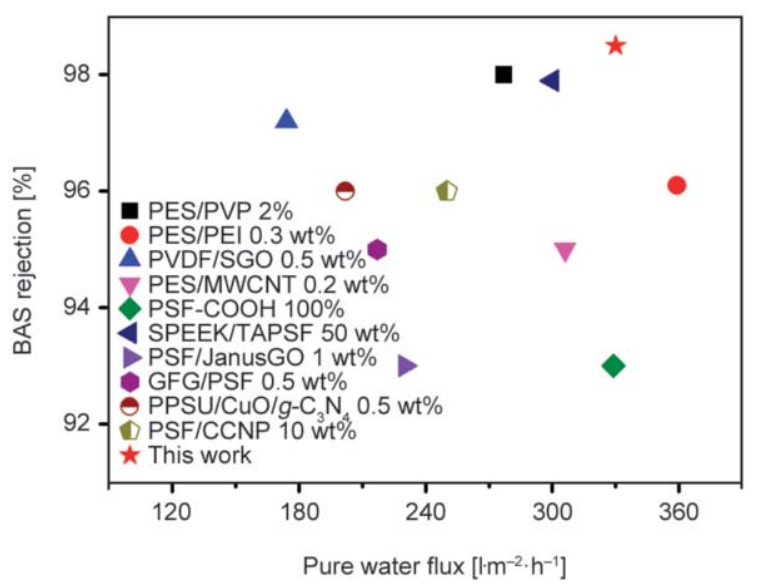

Figure 14. Comparison chart of BSA rejection-pure water flux of UF membranes between M5 and some literatures $[5,30,39,40,45-50]$. of M5 was as high as $330 \mathrm{l} \cdot \mathrm{m}^{-2} \cdot \mathrm{h}^{-1}$ and its BSA rejection maintained above $98 \%$. It successfully broke the serious trade-off effect of other reported UF membranes [51]. The excellent comprehensive performance was closely related to porous Janus PMO$\mathrm{SO}_{3} \mathrm{H} \& \mathrm{SiO}_{2}$-NR nanoparticles used as blending filler. The asymmetry of Janus PMO- $\mathrm{SO}_{3} \mathrm{H} \& \mathrm{SiO}_{2}$-NR nanoparticle in structure and chemical composition achieved a clear division of labor in improving the performance of PES UF membrane, namely, the hydrophobic branch $\left(\mathrm{SiO}_{2}-\mathrm{NR}\right)$ enhanced the compatibility with membrane matrix, and the hydrophilic core $\left(\mathrm{PMO}-\mathrm{SO}_{3} \mathrm{H}\right)$ improved the hydrophilicity of membrane surface.

\section{Conclusions}

In this study, a novel and porous Janus PMO- $\mathrm{SO}_{3} \mathrm{H} \&$ $\mathrm{SiO}_{2}$-NR nanoparticle was successfully synthesized and fully characterized by FTIR, XPS, BET and SEM. Different amounts of porous Janus $\mathrm{PMO}-\mathrm{SO}_{3} \mathrm{H} \&$ $\mathrm{SiO}_{2}$-NR nanoparticles were mixed with PES to prepare mixed matrix membranes (M1, M3, M5) via phase inversion method. In comparison, pristine PES UF membrane (M0) and mixed matrix membrane dopped with porous Janus $\mathrm{PMO} \& \mathrm{SiO}_{2}$ nanoparticle (M3') were also prepared by the same method.

The structural asymmetry of porous Janus PMO$\mathrm{SO}_{3} \mathrm{H} \& \mathrm{SiO}_{2}-\mathrm{NR}$ nanoparticle acheived the diversity of their chemical components. The hydrophilic PMO$\mathrm{SO}_{3} \mathrm{H}$ core directionally and spontaneously migrated to the membrane surface to improve the membrane hydrophilicity, and hydrophobic $\mathrm{SiO}_{2}$-NR branch strongly interacted with the membrane matrix to enhance the compatibility between them. As a result, the obtained mixed matrix membranes showed improved bulk porosity, surface mean pore size, hydrophilicity and permeability. Especially, the pure water flux of M5 was up to $330 \mathrm{l} \cdot \mathrm{m}^{-2} \cdot \mathrm{h}^{-1}$ that was 2.2 times that of the pristine PES membrane (M0) while its rejection maintained above $98.0 \%$. The enhanced permeation flux can be attributed to the synergistic effects of abundant hydrophilic $-\mathrm{SO}_{3} \mathrm{H}$, porous Janus nanoparticle structure as well as the tiny voids between $\mathrm{PMO}-\mathrm{SO}_{3} \mathrm{H} \& \mathrm{SiO}_{2}$-NR and $\mathrm{PES}$ membrane matrix. These were very conducive for water molecules to permeate through the membrane matrix. Meanwhile, there was no compromise on rejection mainly because of two aspects: (1) the appropriate pore size due to the occurance of the delayed phase separation as well as the excellent compatibility 
between porous Janus $\mathrm{PMO}-\mathrm{SO}_{3} \mathrm{H} \& \mathrm{SiO}_{2}-\mathrm{NR}$ nanoparticles and PES membrane matrix; (2) the enhanced hydrophilicity of membrane reducing the amount of hydrophobic BSA penetrating through the UF membrane. Moreover, versus M0 and M3', M5 exhibited the better antifouling performance for BSA solution and long-term performance stability. These owed to the more hydrophilic $-\mathrm{SO}_{3} \mathrm{H}$ that formed a hydration layer on the membrane surface as well as the relatively smooth surface that made the membrane surface easier to clean. Totally, porous Janus $\mathrm{PMO}-\mathrm{SO}_{3} \mathrm{H} \& \mathrm{SiO}_{2}-\mathrm{NR}$ nanoparticles acting as an effective additive open up a new way to prepare mixed matrix membranes for water treatment with excellent comprehensive performance.

\section{Acknowledgements}

The work was financially supported by the Doctoral Scientific Research Starting Foundation of East China University of Technology (DHBK2019116, DHBK2019115), and the Opening Project of Jiangxi Province Key Laboratory of Polymer Micro/Nano Manufacturing and Devices (PMND201904). Special thanks to teacher Wang Xue for her guidance and help on the synthesis of Janus nanoparticles.

\section{References}

[1] Kumar M., Sreedhar N., Jaoude M. A., Arafat H. A.: High-flux, antifouling hydrophilized ultrafiltration membranes with tunable charge density combining sulfonated poly(ether sulfone) and aminated graphene oxide nanohybrid. ACS Applied Materials and Interfaces, 12, 1617-1627 (2020). https://doi.org/10.1021/acsami.9b19387

[2] Chen Z., Du X-A., Liu Y., Ju Y. Y., Song S. K., Dong L. J.: A high-efficiency ultrafiltration nanofibrous membrane with remarkable antifouling and antibacterial ability. Journal of Materials Chemistry A, 6, 1519115199 (2018).

https://doi.org/10.1039/c8ta02649a

[3] Russo F., Galiano F., Pedace F., Aricó F., Figoli A.: Dimethyl isosorbide as a green solvent for sustainable ultrafiltration and microfiltration membrane preparation. ACS Sustainable Chemistry and Engineering, 8, 659668 (2020).

https://doi.org/10.1021/acssuschemeng.9b06496

[4] Salim N. E., Nor N. A. M., Jaafar J., Ismail A. F.: Qtaishat M. R., Matsuura T., Othman M. H. D., Rahman M. A., Aziz F., Yusof N.: Effects of hydrophilic surface macromolecule modifier loading on PES/O-g- $\mathrm{C}_{3} \mathrm{~N}_{4}$ hybrid photocatalytic membrane for phenol removal. Applied Surface Science, 465, 180-191 (2019).

https://doi.org/10.1016/j.apsusc.2018.09.161
[5] Akbari M., Shariaty-Niassar M., Matsuura T., Ismail A. F.: Janus graphene oxide nanosheet: A promising additive for enhancement of polymeric membranes performance prepared vai phase inversion. Journal of Colloid and Interface Science, 527, 10-24 (2018). https://doi.org/10.1016/j.jcis.2018.05.012

[6] Xu C., Yan F., Wang M., Yan H., Cui Z., Li J., He B.: Fabrication of hyperbranched polyether demulsifier modified PVDF membrane for demulsification and separation of oil-in-water emulsion. Journal of Membrane Science, 602, 117974/1-117974/14 (2020). https://doi.org/10.1016/j.memsci.2020.117974

[7] Miller D. J., Dreyer D. R., Bielawski C. W., Paul D. R., Freeman B. D.: Surface modification of water purification membranes. Angewandte Chemie International Edition, 56, 4662-4711 (2017).

https://doi.org/10.1002/anie.201601509

[8] Sandoval-Olvera I. G., González-Muñoz P., Palacio L., Hernández A., Ávila-Rodríguez M., Prádanos P.: Ultrafiltration membranes modified by PSS deposition and plasma treatment for $\mathrm{Cr}(\mathrm{VI})$ removal. Separation and Purification Technology, 210, 371-381 (2019).

https://doi.org/10.1016/j.seppur.2018.08.023

[9] Warsinger D. M., Chakraborty S., Tow E. W., Plumlee M. H., Bellona C., Loutatidou S., Karimi L., Mikelonis A. M., Achilli A., Ghassemi A., Padhye L. P., Snyder S. A., Curcio S., Vecitis C. D., Arafat H. A., Lienhard V. J. H.: A review of polymeric membranes and processes for potable water reuse. Progress in Polymer Science, 81, 209-237 (2018). https://doi.org/10.1016/j.progpolymsci.2018.01.004

[10] Kim D-G., Kang H., Choi Y-S., Han S., Lee J-C.: Photocross-linkable star-shaped polymers with poly(ethylene glycol) and renewable cardanol side groups: Synthesis, characterization, and application to antifouling coatings for filtration membranes. Polymer Chemistry, 4, 50655073 (2013). https://doi.org/10.1039/c3py00756a

[11] Kanagaraj P., Soyekwo F., Mohamed I. M. A., Huang W., Liu C.: Towards improved protein anti-fouling and anti-microbial properties of poly(vinylidene fluoride) membranes by blending with lactate salts-based polyurea as surface modifiers. Journal of Colloid and Interface Science, 567, 379-392 (2020). https://doi.org/10.1016/j.jcis.2020.02.026

[12] Mu Y., Zhu K., Luan J., Zhang S., Zhang C., Na R., Yang Y., Zhang X., Wang G.: Fabrication of hybrid ultrafiltration membranes with improved water separation properties by incorporating environmentally friendly taurine modified hydroxyapatite nanotubes. Journal of Membrane Science, 577, 274-284 (2019). https://doi.org/10.1016/j.memsci.2019.01.043 
[13] Haghighat N., Vatanpour V., Sheydaei M., Nikjavan Z.: Preparation of a novel polyvinyl chloride (PVC) ultrafiltration membrane modified with $\mathrm{Ag} / \mathrm{TiO}_{2}$ nanoparticle with enhanced hydrophilicity and antibacterial activities. Separation and Purification Technology, 237, 116374/1-116374/13 (2020).

https://doi.org/10.1016/j.seppur.2019.116374

[14] Szymański K., Darowna D., Sienkiewicz P., Jose M., Szymańska K., Zgrzebnicki M., Mozia S.: Novel polyethersulfone ultrafiltration membranes modified with $\mathrm{Cu}$ /titanate nanotubes. Journal of Water Process Engineering, 33, 101098/1-101098/14 (2020).

https://doi.org/10.1016/j.jwpe.2019.101098

[15] Zhang X., Zhang T., Ng J., Sun D. D.: High performance multifunctional $\mathrm{TiO}_{2}$ nanowire ultrafiltration membrane with a hierarchical layer structure for water treatment. Advanced Functional Materials, 19, 37313736 (2009).

https://doi.org/10.1002/adfm.200901435

[16] Kumar M., McGlade D., Ulbricht M., Lawler J.: Quaternized polysulfone and graphene oxide nanosheet derived low fouling novel positively charged hybrid ultrafiltration membranes for protein separation. RSC Advances, 5, 51208-51219 (2015). https://doi.org/10.1039/c5ra06893b

[17] Liu Z., Mi Z., Jin S., Wang C., Wang D., Zhao X., Zhou H., Chen C.: The influence of sulfonated hyperbranched polyethersulfone-modified halloysite nanotubes on the compatibility and water separation performance of polyethersulfone hybrid ultrafiltration membranes. Journal of Membrane Science, 557, 13-23 (2018). https://doi.org/10.1016/j.memsci.2018.04.019

[18] Zhu K., Mu Y., Zhang M., Liu Y., Na R., Xu W., Wang G.: Mixed matrix membranes decorated with in situ self-assembled polymeric nanoparticles driven by electrostatic interaction. Journal of Materials Chemistry A, 6, 7859-7870 (2018).

https://doi.org/10.1039/C8TA00317C

[19] Feng Y., Liu Q., Lin X., Liu J. Z., Wang H.: Hydrophilic nanowire modified polymer ultrafiltration membranes with high water flux. ACS Applied Materials and Interfaces, 6, 19161-19167 (2014). https://doi.org/10.1021/am505157w

[20] Yang Y., Ye W., Chen X.: Preparation and controlled assembly of asymmetric Janus particles. Acta PhysicoChimica Sinica, 28, 2525-2535 (2012).

https://doi.org/10.3866/pku.whxb201208222

[21] Vanangamudi A., Dumée L. F., Duke M. C., Yang X.: Nanofiber composite membrane with intrinsic Janus surface for reversed-protein-fouling ultrafiltration. ACS Applied Materials and Interfaces, 9, 18328-18337 (2017).

https://doi.org/10.1021/acsami.7b02382
[22] Zhao Q., Du C., Jia Y., Yuan J., Song G., Zhou X., Sun S., Zhou C., Zhao L., Yang S.: Solar-powered Janus membrane for one-step conversion of sewage to clean water. Chemical Engineering Journal, 387, 124131/1124131/7 (2020). https://doi.org/10.1016/j.cej.2020.124131

[23] Espinosa A., Reguera J., Curcio A., Muñoz Noval A., Kuttner C., Van de Walle A., Liz-Marzán L. M., Wilhelm C.: Janus magnetic plasmonic nanoparticles for magnetically guided and thermally activated cancer therapy. Small, 16, 1904960/1-1904960/14 (2020).

https://doi.org/10.1002/smll.201904960

[24] Singh A. K., Bhuyan T., Maity S., Mandal T. K., Bandyopadhyay D.: Magnetically actuated carbon soot nanoparticle-based catalytic CARBOts coated with $\mathrm{Ni} / \mathrm{Pt}$ nanofilms for water detoxification and oil-spill recovery. ACS Applied Nano Materials, 3, 3459-3470 (2020). https://doi.org/10.1021/acsanm.0c00199

[25] Pradhan S., Ghosh D., Chen S. W.: Janus nanostructures based on $\mathrm{Au}-\mathrm{TiO}_{2}$ heterodimers and their photocatalytic activity in the oxidation of methanol. ACS Applied Materials and Interfaces, 1, 2060-2065 (2009). https://doi.org/10.1021/am900425v

[26] Hong B., Fan H., Cheng X-B., Yan X., Hong S., Dong Q., Gao C., Zhang Z., Lai Y., Zhang Q.: Spatially uniform deposition of lithium metal in 3D Janus hosts. Energy Storage Materials, 16, 259-266 (2019). https://doi.org/10.1016/j.ensm.2018.04.032

[27] Yang H-C., Hou J., Chen V., Xu Z-K.: Janus membranes: Exploring duality for advanced separation. Angewandte Chemie International Edition, 55, 13398-13407 (2016). https://doi.org/10.1002/anie.201601589

[28] He X., Liang C., Liu Q., Xu Z.: Magnetically responsive Janus nanoparticles synthesized using cellulosic materials for enhanced phase separation in oily wastewaters and water-in-crude oil emulsions. Chemical Engineering Journal, 378, 122045/1-122045/17 (2019). https://doi.org/10.1016/j.cej.2019.122045

[29] Wang X., Guan B., He Y., Zhang Y., Cao Y., Liu Y., Qiao Z-A., Huo Q.: Synthesis of Janus mesoporous silica nanostructures with organic-inorganic hybrid components through a sprout-like growth method. ChemNanoMat, 1, 562-566 (2015). https://doi.org/10.1002/cnma.201500128

[30] Liu Z., Mi Z., Chen C., Zhou H., Zhao X., Wang D.: Preparation of hydrophilic and antifouling polysulfone ultrafiltration membrane derived from phenolphthalin by copolymerization method. Applied Surface Science, 401, 69-78 (2017).

https://doi.org/10.1016/j.apsusc.2016.12.228 
[31] Mi Z., Liu Z., Wang C., Liu Y., Zhou C., Wang D., Zhao X., Zhou H., Zhang Y., Chen C.: Transparent and soluble polyimide films containing 4,4'-isopropylidenedicyclohexanol (Cis-HBPA) units: Preparation, characterization, thermal, mechanical, and dielectric properties. Journal of Polymer Science Part A: Polymer Chemistry, 56, 2115-2128 (2018).

https://doi.org/10.1002/pola.29172

[32] Mi Z., Wang S., Hou Z., Liu Z., Jin S., Wang X., Wang D., Zhao X., Zhang Y., Zhou H., Chen C.: Soluble polyimides bearing (cis, trans)-hydrogenated bisphenol a and (trans, trans)-hydrogenated bisphenol a moieties: Synthesis, properties and the conformational effect. Polymers, 11, 854/1-854/19 (2019). https://doi.org/10.3390/polym11050854

[33] Liu Z., Mi Z., Meng S., Sun N., Zhao X., Wang D., Zhou H., Chen C.: Influence of 1:4;3:6-dianhydro-dmannitol-based polyamide as an additive on morphology, permeability and antifouling performance of PES ultrafiltration membrane. High Performance Polymers, 30, 1147-1158 (2018). https://doi.org/10.1177/0954008317741949

[34] Ondračka P., Nečas D., Carette M., Elisabeth S., Holec D., Granier A., Goullet A., Zajíčková L., Richard-Plouet M.: Unravelling local environments in mixed $\mathrm{TiO}_{2}$ $\mathrm{SiO}_{2}$ thin films by XPS and ab initio calculations. Applied Surface Science, 510, 145056/1-145056/11 (2020).

https://doi.org/10.1016/j.apsusc.2019.145056

[35] Wang N., Huang Z., Li X., Li J., Ji S., An Q-F.: Tuning molecular sieving channels of layered double hydroxides membrane with direct intercalation of amino acids. Journal of Materials Chemistry A, 6, 17148-17155 (2018). https://doi.org/10.1039/C8TA06233A

[36] Sun H., Tang B., Wu P.: Hydrophilic hollow zeolitic imidazolate framework-8 modified ultrafiltration membranes with significantly enhanced water separation properties. Journal of Membrane Science, 551, 283 293 (2018).

https://doi.org/10.1016/j.memsci.2018.01.053

[37] Ayyaru S., Ahn Y-H.: Application of sulfonic acid group functionalized graphene oxide to improve hydrophilicity, permeability, and antifouling of PVDF nanocomposite ultrafiltration membranes. Journal of Membrane Science, 525, 210-219 (2017).

https://doi.org/10.1016/j.memsci.2016.10.048

[38] Zhang L., Cui Z., Hu M., Mo Y., Li S., He B., Li J.: Preparation of PES/SPSf blend ultrafiltration membranes with high performance vai $\mathrm{H}_{2} \mathrm{O}$-induced gelation phase separation. Journal of Membrane Science, 540, 136-145 (2017).

https://doi.org/10.1016/j.memsci.2017.06.044
[39] Zhu K., Zhang S., Luan J., Mu Y., Du Y., Wang G.: Fabrication of ultrafiltration membranes with enhanced antifouling capability and stable mechanical properties vai the strategies of blending and crosslinking. Journal of Membrane Science, 539, 116-127 (2017).

https://doi.org/10.1016/j.memsci.2017.05.061

[40] Arumugham T., Amimodu R. G., Kaleekkal N. J., Rana D.: Nano $\mathrm{CuO} / g-\mathrm{C}_{3} \mathrm{~N}_{4}$ sheets-based ultrafiltration membrane with enhanced interfacial affinity, antifouling and protein separation performances for water treatment application. Journal of Environmental Sciences, 82, 5769 (2019).

https://doi.org/10.1016/j.jes.2019.03.001

[41] Yi X., Zhu Y., Wang D., Yang F., Wang Y., Shi W.: Adsorption mechanism of oil-in-water on a $\mathrm{TiO}_{2} / \mathrm{Al}_{2} \mathrm{O}_{3}-$ polyvinylidene fluoride (PVDF) ultrafiltration membrane. Langmuir, 34, 9907-9916 (2018).

https://doi.org/10.1021/acs.langmuir.8b01222

[42] Yang C., Xu W., Nan Y., Wang Y., Gao C., Hu Y., Chen $\mathrm{X}$.: Preparation and characterization of acid and solvent resistant polyimide ultrafiltration membrane. Applied Surface Science, 483, 278-284 (2019).

https://doi.org/10.1016/j.apsusc.2019.03.226

[43] Lavanya C., Balakrishna R. G.: Naturally derived polysaccharides-modified PSF membranes: A potency in enriching the antifouling nature of membranes. Separation and Purification Technology, 230, 115887/1115887/12 (2020).

https://doi.org/10.1016/j.seppur.2019.115887

[44] Ghiasi S., Behboudi A., Mohammadi T., Khanlari S.: Effect of surface charge and roughness on ultrafiltration membranes performance and polyelectrolyte nanofiltration layer assembly. Colloids and Surfaces A: Physicochemical and Engineering Aspects, 580, 123753/1123753/15 (2019).

https://doi.org/10.1016/j.colsurfa.2019.123753

[45] Jalali A., Shockravi A., Vatanpour V., Hajibeygi M.: Preparation and characterization of novel microporous ultrafiltration PES membranes using synthesized hydrophilic polysulfide-amide copolymer as an additive in the casting solution. Microporous and Mesoporous Materials, 228, 1-13 (2016).

https://doi.org/10.1016/j.micromeso.2016.03.024

[46] Fang X., Li J., Li X., Sun X., Shen J., Han W., Wang L.: Polyethyleneimine, an effective additive for polyethersulfone ultrafiltration membrane with enhanced permeability and selectivity. Journal of Membrane Science, 476, 216-223 (2015). https://doi.org/10.1016/j.memsci.2014.11.021

[47] Miao W., Li Z-K., Yan X., Guo Y-J., Lang W-Z.: Improved ultrafiltration performance and chlorine resistance of PVDF hollow fiber membranes vai doping with sulfonated graphene oxide. Chemical Engineering Journal, 317, 901-912 (2017).

https://doi.org/10.1016/j.cej.2017.02.121 
[48] Zhu K., Wang G.: Fabrication of high-performance ultrafiltration membranes using zwitterionic carbon nanotubes and polyethersulfone. High Performance Polymers, 30, 602-611 (2017).

https://doi.org/10.1177/0954008317711234

[49] Zhang G., Zhou M., Xu Z., Jiang C., Shen C., Meng Q.: Guanidyl-functionalized graphene/polysulfone mixed matrix ultrafiltration membrane with superior permselective, antifouling and antibacterial properties for water treatment. Journal of Colloid and Interface Science, 540, 295-305 (2019).

https://doi.org/10.1016/j.jcis.2019.01.050
[50] Ouyang G., Hussain A., Li J., Li D.: Remarkable permeability enhancement of polyethersulfone (PES) ultrafiltration membrane by blending cobalt oxide/ graphene oxide nanocomposites. RSC Advances, 5, 70448-70460 (2015).

https://doi.org/10.1039/C5RA11349K

[51] Zhao J., Wang Q., Yang J., Li Y., Liu Z., Zhang L., Zhao Y., Zhang S., Chen L.: Comb-shaped amphiphilic triblock copolymers blend PVDF membranes overcome the permeability-selectivity trade-off for protein separation. Separation and Purification Technology, 239, 116596/1-116596/11 (2020).

https://doi.org/10.1016/j.seppur.2020.116596 